OPEN ACCESS

Edited by:

Kenichi Ikejima,

Juntendo University, Japan

Reviewed by:

Roberto Gramignoli, Karolinska Institute (KI), Sweden

Taro Takami,

Yamaguchi University, Japan

*Correspondence:

Abdulrahman Ismaiel

abdulrahman.ismaie/@yahoo.com

Specialty section:

This article was submitted to

Gastroenterology,

a section of the journal

Frontiers in Medicine

Received: 12 April 2019

Accepted: 27 August 2019

Published: 13 September 2019

Citation:

Ismaiel A and Dumitraşcu DL (2019)

Cardiovascular Risk in Fatty Liver

Disease: The Liver-Heart

Axis-Literature Review.

Front. Med. 6:202.

doi: 10.3389/fmed.2019.00202

\section{Cardiovascular Risk in Fatty Liver Disease: The Liver-Heart Axis-Literature Review}

\author{
Abdulrahman Ismaiel ${ }^{1,2 *}$ and Dan L. Dumitraşcu ${ }^{1,2}$ \\ ${ }^{1}$ Iuliu Haţieganu University of Medicine and Pharmacy, Cluj-Napoca, Romania, ${ }^{2}$ 2nd Department of Internal Medicine, \\ Cluj-Napoca, Romania
}

According to the World Health Organization, cardiovascular disease (CVD) remains the leading cause of death worldwide, accounting for approximately 18 million deaths per year. Nevertheless, the worldwide prevalence of metabolic diseases, such as type 2 diabetes mellitus, obesity, and non-alcoholic fatty liver disease (NAFLD), also known to be common risk factors for CVD, have dramatically increased over the last decades. Chronic alcohol consumption is a major cause of chronic liver diseases (CLD) as well as being a major health care cost expenditure accounting for the spending of tremendous amounts of money annually. NAFLD has become one of the major diseases plaguing the world while standing as the most common cause of liver disease in the Western countries by representing about $75 \%$ of all CLD. Currently, the most common cause of death in NAFLD remains to be CVD. Several mechanisms have been suggested to be responsible for associating FLD with CVD through several mechanisms including low-grade systemic inflammation, oxidative stress, adipokines, endoplasmic reticulum stress, lipotoxicity and microbiota dysbiosis which may also be influenced by other factors such as genetic and epigenetic variations. Despite of all this evidence, the exact mechanisms of how FLD can causally contribute to CVD are not fully elucidated and much remains unknown. Moreover, the current literature supports the increasing evidence associating FLD with several cardiovascular (CV) adverse events including coronary artery disease, increased subclinical atherosclerosis risk, structural alterations mainly left ventricular hypertrophy, increased epicardial fat thickness, valvular calcifications including aortic valve sclerosis and mitral annular calcification and functional cardiac modifications mainly diastolic dysfunction in addition to cardiac arrhythmias such as atrial fibrillation and ventricular arrythmias and conduction defects including atrioventricular blocks and bundle branch blocks. Patients with FLD should be evaluated and managed accordingly in order to prevent further complications. Possible management methods include non-pharmacological strategies including life style modifications, pharmacological therapies as well as surgical management. This review aims to summarize the current state of knowledge regarding the pathophysiological mechanisms linking FLD with an increased CV risk, in addition to associated CV adverse events and current management modalities.

Keywords: cardiovascular disease (CV disease), non-alcoholic fatty liver disease (NAFLD), alcoholic liver disease (ALD), cardiac arrhythmias, metabolic syndrome (MetS) 


\section{KEY CONCEPTS}

- Both alcoholic and non-alcoholic fatty liver diseases are associated with intrahepatic and extrahepatic manifestations such as fatal and non-fatal cardiovascular diseases, leading to an increased morbidity and mortality.

- Features of the MetS are frequently present in non-alcoholic fatty liver disease (NAFLD) patients associating them with a higher $\mathrm{CV}$ risk.

- Several factors have been described as possible pathogenic factors playing a role in the explanation of the complex relationship associating CVD with FLD such as insulin resistance, systemic inflammation, cytokines, oxidative stress, adipokines, hepatokines, genes, and intestinal microbiota, as well as several other factors.

- Although the current evidence supports the association between FLD and an increased cardiovascular risk, the presence of a causal association remains to be proved.

- Further research is required in order to confirm the causal pathogenic links associating FLD with an increased cardiovascular risk.

- Current convincing evidence describes the relationship associating fatty liver disease (FLD) with an increased cardiovascular risk described by subclinical atherosclerosis in addition to cardiac structural and functional abnormalities.

- Subclinical atherosclerosis demonstrated to be related to FLD consists of coronary artery disease as well as increased carotid intima media thickness and the presence of carotid plaques.

- Structural cardiac alterations associated with FLD include left ventricular hypertrophy, increased epicardial fat thickness, valvular calcifications including aortic valve sclerosis and mitral annular calcification.

- Functional cardiac abnormalities linked to FLD include cardiac arrhythmias of both atrial and ventricular origin in addition to conduction defects including atrioventricular blocks and bundle branch blocks.

- A multidisciplinary patient centered and personalized medicine approach is required to provide FLD patients with the best management.

- Lifestyle changes such as weight loss, exercise and dietary changes are considered the cornerstone in managing FLD patients.

- Possible pharmacological therapies include anti-diabetic drugs such as metformin, SGLT2 inhibitors, PPAR $\gamma$ and GLP-1 agonists, lipid lowering medications mainly statins as well as renin angiotensin system inhibitors.

\footnotetext{
Abbreviations: AF, Atrial Fibrillation; AFL, Alcoholic Fatty Liver; AFLD, Alcoholic fatty liver disease; ALD, Alcoholic Liver Disease; ALT, Alanine transaminase; ASH, Alcoholic Steatohepatitis; BMI, Body Mass Index; CAC, Coronary Artery Calcium; CAD, Coronary Artery Disease; CIMT, Carotid Intima Media Thickness; CLD, Chronic Liver Disease; CRP, C-reactive Protein; CV, Cardiovascular; CVD, Cardiovascular Disease; EFT, Epicardial Fat Thickness; FLD, Fatty liver disease; GGT, Gamma-glutamyltransferase; HbA1c, Glycated hemoglobin; HDL, High Density Lipoproteins; IR, Insulin Resistance; LV, Left Ventricular; MetS, Metabolic Syndrome; NAFL, Non-alcoholic Fatty Liver; NAFLD, Non-alcoholic Fatty Liver Disease; NASH, Non-alcoholic steatohepatitis; VAT, Visceral Adipose Tissue.
}

- Surgical management remains of limited use due to its invasiveness, high costs and possible complications.

\section{INTRODUCTION}

According to the World Health Organization, the most common cause of death worldwide is cardiovascular disease (CVD), accounting for an estimated 18 million deaths per year (1). Nevertheless, a dramatic worldwide increase in the prevalence of metabolic diseases such as non-alcoholic fatty liver disease (NAFLD), type 2 diabetes mellitus and obesity, that are known risk factors for CVD, has been observed.

Chronic liver diseases (CLD) contribute for a major burden to both morbidity and mortality worldwide with a significant impact on public health. Fatty liver disease (FLD) is composed of a wide spectrum including alcoholic liver disease (ALD) and non-alcoholic fatty liver disease (NAFLD). Currently, ALD is the second most common indication for liver transplantation for CLD in the Western world. Nevertheless, NAFLD is expected to become the main cause for liver transplantation within 10 years (2).

Chronic alcohol consumption is a major cause of CLD as well as being a major health care cost expenditure accounting for the spending of tremendous amounts of money annually (3). NAFLD has become one of the major diseases plaguing the world while standing as the most common cause of liver disease in the Western countries by representing approximately $75 \%$ of the chronic liver disease (4). A recent meta-analysis with a total number of 8,515,431 patients reported that the global prevalence of NAFLD is $25.24 \%$ with highest prevalence in the Middle East and South America and lowest in Africa (5). In Romania, the prevalence of NAFLD was found to be $20 \%$ of 3,005 hospitalized patients not known to have liver disease (6).

Several studies demonstrated the presence of a direct association between NAFLD and CVD suggesting that NALFD should be considered a significant independent risk factor in the absence of traditional cardiovascular $(\mathrm{CV})$ risk factors and metabolic syndrome for subclinical and clinical CVD $(7,8)$. Alcoholic hyperlipidemia, associated with its thrombogenic, proinflammatory and pro-coagulative effects, is a definite CV risk factor in drinkers (9).

The current literature demonstrated an association between NAFLD and CV complications such as coronary arteries disease (CAD), subclinical atherosclerosis, and cardiac arrythmias as well as conduction, structural and functional alterations (10). This additional CVD related to NAFLD can further contribute to an increased CV morbidity and mortality (11). The pathogenic factors associated with fatty liver disease are multifactorial (12). These include inflammation, adipokines, intestinal dysbiosis, genetics, oxidative stress as well as psychological stress such as anxiety and depression (13) among others which are all established markers for CVD. This indicates the need for further research and measures to be undertaken in order to reduce the burden caused by FLD.

In this review, we summarize the current NAFLD and ALD definitions in addition to general considerations correlating 
FLD with CVD. We also discuss possible risk factors and pathophysiological mechanisms that might be associating FLD with CVD. Moreover, we also focus on the updates recently published in the expeditiously increasing clinical evidence associating FLD with CAD, subclinical atherosclerosis risk, structural and functional cardiac modifications in addition to cardiac arrhythmias and conduction defects. Lastly, we will be discussing current updates related to possible management modalities. We believe that this review provides health-care professionals with an update on CVD in patients with FLD in order to provide patients with the required CV screening and evaluation methods, in addition to management strategies.

\section{NON-ALCOHOLIC FATTY LIVER DISEASE AND ALCOHOLIC LIVER DISEASE}

\section{Non-alcoholic Fatty Liver Disease}

NAFLD is defined by imagistic or histological presence of hepatic steatosis and the absence of other secondary causes of hepatic fat accumulation such as significant alcohol consumption and other causes mentioned in Table 1 (12). Histologically, NAFLD is considered present when $\geq 5 \%$ of the liver cells contain fat and is considered severe when $\geq 30 \%$ of liver cells contain fat on liver biopsy $(14,15)$. The term NAFLD includes the entire spectrum of FLD as described in Table 2 according to the American Association for the Study of Liver Diseases (16). The spectrum includes non-alcoholic fatty liver (NAFL), nonalcoholic steatohepatitis (NASH) and liver cirrhosis.

\section{Alcoholic Liver Disease}

ALD is defined by imagistic or histological presence of hepatic steatosis associated with significant alcohol consumption of $\geq 20$ grams per day for women and $\geq 30$ grams per day for men; 10 grams of alcohol is equivalent to 4 ounces of wine, 1.5 ounces of hard liquor and 12 ounces of beer (17). The term ALD includes the entire spectrum of FLD as defined in Table 3 starting from

TABLE 1 | Common causes of secondary hepatic steatosis.

\section{MACROVESICULAR STEATOSIS}

- Significant alcohol consumption

- Hepatitis C (especially genotype 3)

- Wilson's Disease

- Lipodystrophy

- Starvation

- Parenteral nutrition

- Abetalipoproteinemia

- Medications (e.g., amiodarone, methotrexate, tamoxifen, corticosteroids, mipomersen, lomitapide)

\section{MICROVESICULAR STEATOSIS}

- Reye's syndrome

- Acute fatty liver of pregnancy

- HELLP syndrome

- Metabolic disorders (e.g., lecithin-cholesterol-acyltransferase (LCAT) deficiency, cholesterol ester storage disease, Wolman's disease)

- Medications (e.g., valproate, antiretroviral drugs) alcoholic fatty liver (AFL), alcoholic steatohepatits (ASH) and reaching to alcoholic liver cirrhosis $(18,19)$.

\section{FATTY LIVER DISEASE, METABOLIC SYNDROME AND TYPE 2 DIABETES}

Metabolic syndrome (MetS) is an important risk factor that identifies subjects with an increased susceptibility of developing future type 2 diabetes and CVD. It is defined by the presence of three of the five criteria mentioned in Table 4 (20). Features of the MetS are frequently met in patients with NAFLD linking it to an increase CV risk (21). Almost $90 \%$ of patients with NAFLD will present with at least one of the features of MetS and about $33 \%$ will fulfill the criteria for diagnosing MetS (22). A recent study that took place in 19 European centers demonstrated a significant association between decreased insulin sensitivity and an increased incidence of CVD in patients with NAFLD (23). Rocha et al. conducted a study on NAFLD patients demonstrating that $98 \%$ of these patients were insulin resistant which is considered a landmark of MetS, while 39\% of these patients

TABLE 2 | Non-alcoholic fatty liver disease spectrum and definitions.

NAFLD
Spectrum

Non-alcoholic fatty liver

The presence of $\geq 5 \%$ hepatic steatosis in the absence of hepatocellular injury manifested by hepatocyte ballooning. It is associated with a minimal progression risk of cirrhosis and liver failure.

Non-alcoholic The presence of $\geq 5 \%$ hepatic steatosis and inflammation steatohepatitis with hepatocyte injury manifested by hepatocyte ballooning, in the presence or absence of liver fibrosis. It is associated with a progression risk to liver cirrhosis, liver failure and can rarely lead to liver cancer.

Non-alcoholic The presence of liver cirrhosis with previous or current steatohepatitis histological evidence of steatosis or steatohepatitis. cirrhosis

Cryptogenic The presence of liver cirrhosis without any obvious etiology. It cirrhosis is most commonly associated with metabolic risk factors such as metabolic syndrome and obesity.

TABLE 3 | Alcoholic liver disease spectrum and definitions.

\begin{tabular}{|c|c|}
\hline $\begin{array}{l}\text { ALD } \\
\text { Spectrum }\end{array}$ & Definitions \\
\hline $\begin{array}{l}\text { Alcoholic fatty } \\
\text { liver }\end{array}$ & $\begin{array}{l}\text { Increased hepatic fat deposition due to significant alcohol } \\
\text { consumption. The average weight for a healthy liver is } 1.5 \mathrm{~kg} \\
\text { and is heavier in patients with alcoholic fatty liver reaching to } \\
\text { about } 2.0-2.5 \mathrm{~kg} \text {. }\end{array}$ \\
\hline $\begin{array}{l}\text { Alcoholic } \\
\text { steatohepatitis }\end{array}$ & $\begin{array}{l}\text { A form of toxic liver disease due to chronic excessive alcohol } \\
\text { consumption. It is defined histologically by the presence of } \\
\text { steatosis, necrosis, inflammation with infiltration of } \\
\text { polymorphic granulocytes and fibrosis associated with } \\
\text { intracellular Mallory-Denk bodies. }\end{array}$ \\
\hline $\begin{array}{l}\text { Alcoholic liver } \\
\text { cirrhosis }\end{array}$ & $\begin{array}{l}\text { It is defined by a continuous deposition of extracellular matrix } \\
\text { and fibrosis associated with the generation of regenerative } \\
\text { nodules, in addition to a parallel destruction of the hepatic } \\
\text { lobule's normal structure. It represents the irreversible end } \\
\text { stage of alcoholic liver disease. }\end{array}$ \\
\hline
\end{tabular}


TABLE 4 | Metabolic syndrome criteria*

\begin{tabular}{ll}
\hline Criteria & Definition \\
\hline $\begin{array}{l}\text { Waist } \\
\text { circumference }\end{array}$ & $\geq 102 \mathrm{~cm}$ (40 in) in men or $\geq 88 \mathrm{~cm}$ (35 in) in women \\
$\begin{array}{l}\text { Triglyceride } \\
\text { level }\end{array}$ & $\geq 150 \mathrm{mg} / \mathrm{dL}$ (or receiving drug therapy for hypertriglyceridemia) \\
$\begin{array}{l}\text { Blood } \\
\text { pressure }\end{array}$ & $\geq 130 / 85 \mathrm{mmHg}$ (or receiving drug therapy for hypertension) \\
HDL & $<40 \mathrm{mg} / \mathrm{dL}$ in men or $<50 \mathrm{mg} / \mathrm{dL}$ in women (or receiving drug \\
cholesterol & therapy for reduced HDL cholesterol) \\
Fasting blood & $\geq 100 \mathrm{mg} / \mathrm{dL}$ (or receiving drug therapy for hyperglycemia) \\
sugar &
\end{tabular}

*Metabolic Syndrome is diagnosed when an individual has at least 3 of the 5 previously mentioned criteria.

were diabetic in addition to a marked increase in body mass index (BMI) and waist/hip ratio (24). These results were also confirmed by a recently published meta-analysis demonstrating an association between NAFLD with insulin resistance and diabetes (25). They also added that NAFLD predicted the development of diabetes. While type 2 diabetes mellitus can predict the development of NAFLD and vice versa and each factor can act as a progression factor for the other, the exact association between them remains poorly understood. Moreover, wide spectrums of liver diseases related to NAFLD are associated with obesity such as hepatic steatosis, fibrosis and cirrhosis (26).

On the other hand, the protective association of alcohol consumption in CVD remains elusive and inconsistent. The current literature describing ALD has demonstrated an association between alcohol intake and incident type 2 diabetes mellitus (27) or frank type 2 diabetes mellitus due to chronic pancreatitis (28). Moreover, several studies demonstrated that alcohol consumption is associated with an increased risk of cancers and intracerebral hemorrhage, especially in elderly subjects (29-31). Certainly, the relationship between alcohol consumption and obesity in the risk of advanced liver disease and cirrhosis is complex. This is because moderate consumption of alcohol may improve insulin sensitivity and other metabolic parameters which are factors that might reduce the development of NAFLD, whereas heavier alcohol consumption may be additive with NAFLD in the risk of progression to cirrhosis. Several important modifiers related to cardiac effects of alcohol are possibly involved in this mechanistic correlation including drinking patterns, type of consumed alcohol, socio-economic status, education, and dietary patterns. Alcohol consumption might have different outcomes according to several factors including the patients' associated comorbidities. Therefore, an assessment of non-cardiovascular effects associated with alcohol consumption should also be performed when evaluating the potential CV risks and benefits associated with alcohol use.

\section{PATHOPHYSIOLOGICAL MECHANISMS OF CARDIOVASCULAR DISEASE IN FATTY LIVER DISEASE}

The complex relationship between FLD and CVD and the mechanistic associations are not yet fully understood which requires further research in this field. Several factors have been described as possible pathogenic causes playing a role in the explanation of this complex relationship associating CVD with FLD as described in Figure 1. Metabolic disorders such as FLD and type 2 diabetes mellitus are known to cause a low-grade systemic inflammation leading to several extrahepatic complications including an increased CV risk (32). Several mechanisms have been suggested to stand behind the presence of this systemic inflammation including oxidative stress, endoplasmic reticulum stress, lipotoxicity and gut microbiota alterations. These mechanisms may also be influenced by other factors such as genetic and epigenetic variations (33-36).

\section{Inflammation, Cytokines, and Oxidative Stress}

The liver is an essential metabolic organ taking part in the systemic inflammation possibly through secreting inflammatory markers, chemokines and cytokines being drained into the systemic circulation, leading to secondary CV adverse through endothelial dysfunction, enhanced plaque formation, altered vascular tone and coagulation. Several inflammatory markers and cytokines have been demonstrated to be related to FLD and an increased $\mathrm{CV}$ risk such as serum levels of tumor necrosis factor (TNF)- $\alpha$, interleukin (IL)-6, CCL3, soluble intercellular adhesion molecule-1 (sICAM-1) and C-reactive protein (CRP) as well as elevated hepatic expression of IL-6, TNF, CXCL10 and IL1RN $(37,38)$. Worsening inflammatory and insulin resistance (IR) states are associated with worse cardiometabolic outcomes seen in increasing severity of NAFLD.

Oxidation is an essential process for the human body to fight off pathogens, while oxidative stress, a marker of NAFLD, is due to an alteration of the free radical activity and antioxidant activity. This imbalance leads to multiple diseases because of the abnormal release of cytokines such as TNF- $\alpha$, CRP, and IL-6. Studies suggest that oxidative stress may be involved in the pathogenesis of CVD in patients with FLD through these processes (39) while contributing to the progression of liver disease severity from simple steatosis to steatohepatitis (40).

\section{Insulin Resistance}

IR described as an abnormal cell response to insulin hormone, is one of the principal risk factors demonstrated to be associated with NAFLD, MetS and atherosclerosis. It is suggested that IR evolution might be the principal factor associated with the initiation NAFLD, mainly due to metabolic modifications in glucose, fatty acid and lipoprotein (37). Moreover, hyperinsulinemia was demonstrated to cause an altered cardiometabolic cascade by worsening IR and abnormal insulin signaling in involved tissues (41). The presence of subclinical inflammation, altered adipokines and the presence of increased ectopic fat accumulation in organs can further provoke IR being associated with an increased risk of adverse CV events.

\section{Dislipidemia and Postprandial Hyperlipidemia}

The liver is the main organ in the body responsible for regulating the lipid metabolism process (42). The liver tends to decrease the liver fat by performing a limited compensatory mechanism 


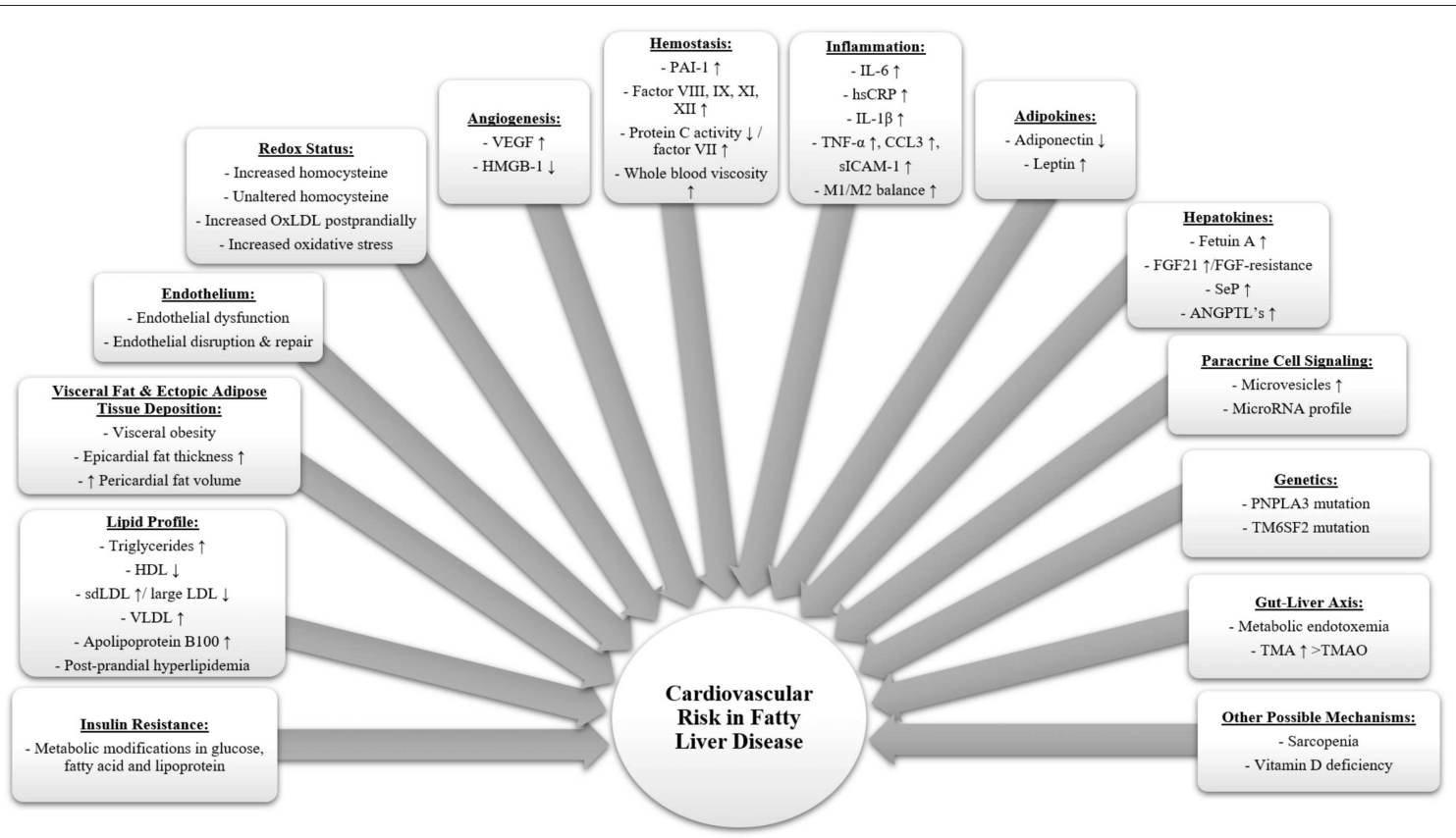

FIGURE 1 | Summary of potential pathophysiological mechanisms associating fatty liver disease with an increased cardiovascular risk. Fatty liver disease leads to multiple alterations in the human body as summarized in this figure, ultimately causing several complications including cardiovascular disease. Low grade systemic inflammation plays an essential role in the development of fatty liver disease. It can be explained by several intertwined factors such as diet, gut, microbiota, genes, visceral adipose tissue and liver. (ANGPTL, Angiopoietin like proteins; FGF21, Fibroblast growth factor 21; HDL, High-density lipoproteins; HMGB-1, High mobility group box 1; hsCRP, High sensitivity C-reactive protein; IL-1b, Interleukin 1b; IL-6, Interleukin 6; LDL, Low density lipoprotein; M1/M2, Macrophage phenotype 1/2 ratio; OxLDL, Oxidized low-density lipoprotein; PAI-1, Plasminogen activator inhibitor 1; PNPLA3, Patatin-like phospholipase domain containing protein 3; sdLDL, Small dense low-density lipoproteins; SeP, Selenoprotein P; sICAM-1, Soluble intercellular adhesion molecule-1; TM6SF2, Transmembrane 6 superfamily member 2; TMA, Trimethylamine; TMAO, Trimethylamine-N-Oxide; TNF $\alpha$, Tumor necrosis factor a; VEGF, Vascular endothelial growth factor; VLDL, Very low-density lipoprotein).

through increasing liver production of triglyceride (TG) rich very low-density lipoprotein (VLDL) (43) which leads to a reduction in high-density lipoprotein (HDL) levels due to an imbalance in the HDL metabolism. Serum lipid profile is significantly related to the severity of NAFLD demonstrating more alterations in NASH. NAFLD is characterized by an atherogenic lipid profile consisting of high TG levels, low HDL cholesterol, high lowdensity lipoprotein (LDL) levels, high VLDL levels and high apolipoprotein B100 concentration leading to a significantly increased CV risk (44).

FLD patients can present with postprandial hyperlipidemia defined by elevated TG-rich chylomicron remnants postprandially in addition to a prolonged hypertriglyceridemia which was demonstrated to be associated with postprandial atherogenesis and an increased CV risk (45-47).

\section{Adipokines}

Adipokines are hormones produced by fat tissue influencing the CV system through exerting a direct effect on the vascular wall via paracrine action or affecting endothelial function through an imbalance of plasma and tissue levels of adipokines. Alterations in circulating adipokines such as decreased adiponectin or increased leptin levels were reported in MetS and NAFLD (48). Several adipokines have been demonstrated to present with anti-inflammatory and cardioprotective effects such as omentin, apelin, adiponectin. On the other hand, leptin, visfatin, resistin and adipocyte fatty-acidbinding protein were found to have pro-inflammatory effects exerting a negative impact on the $\mathrm{CV}$ function increasing the risk of CVD (49).

\section{Gut Microbiota}

Several factors can modify the enormously complex, dynamic, and vast gut microbiota present in the human body including FLD, diabetes and obesity, leading to adverse CV outcomes (50). Several studies demonstrated that metabolic endotoxemia caused by lipopolysaccharide (LPS) exposure and the binding to toll-like receptor 4 (TLRs) can promote a systemic lowgrade inflammation and activate an immune response leading to the release of pro-inflammatory markers (51). This process promotes endothelial dysfunction, oxidation of LDLs and thrombogenesis, in addition to the formation and rupture of atherosclerotic plaques (51). Several novel metabolites studied through metabolomic analyses were found to be associated with an increased $\mathrm{CV}$ risk such as phosphatidylcholine (PC) metabolism including choline, betaine, and trimethylamine $\mathrm{N}$-oxide (TMAO) (52). Moreover, TMAO levels were demonstrated to able to predict major adverse cardiac events independently from traditional CV risk factors (53). 


\section{Genetics}

A couple of genes seem to be of interest in relation to FLD and $\mathrm{CV}$ risk including patatin-like phospholipase domain containing protein 3 (PNPLA3) and transmembrane 6 superfamily member 2 (TM6SF2). PNPLA3 rs738409 mutation was found to be related to the severity of NAFLD and TG metabolism leading to lower plasma lipids, while causing a modest, negative association between PNPLA3 and CAD $(38,54)$. TM6SF2 may predispose to NAFLD and liver fibrosis because of its role leading to triglycerides and cholesterol retention in the liver. Surprisingly with this mutation, a cardioprotective role described as the "Catch-22" paradigm has been demonstrated due to reduced levels of VLDL secretion and improved serum TG levels with an unaltered insulin sensitivity (38).

\section{Visceral Fat and Ectopic Adipose Tissue Distribution}

Visceral adipose tissue (VAT) is a hormonally active endocrine organ associated with unique biochemical characteristics. It secretes pro-inflammatory cytokines, adipokines and hormones that influence several normal and pathological processes including inflammation and IR (55). The presence of an increased amount of visceral adipose tissue deposition is known as visceral obesity, also known to be associated with several pathologies and risk factors such as MetS and CVD. Studies demonstrated an independent association linking increased liver fat with VAT (56) leading to an increased CV risk, recently assessed and found to be related to plaque calcifications presence and increased CVD (57). Moreover, central obesity is independently associated with an increased cardiovascular morbidity and mortality (58). Furthermore, several known CV risk factors including impaired glucose tolerance, IR and dyslipidemia were demonstrated to be independently associated with an increased VAT mass $(59,60)$.

Ectopic fat accumulation in the heart possibly evaluated by the presence of an increased epicardial fat thickness (EFT) or increased pericardial fat volume, is demonstrated to be associated with several $\mathrm{CV}$ risk factors including visceral fat, IR and MetS leading to an increased risk of adverse CV events such as $\operatorname{CAD}(37,61,62)$. Moreover, an independent relationship linking NAFLD with ectopic hepatic fat has been studied (63). Furthermore, pericardial fat volume was found to be an independent predictive factor in asymptomatic subjects with major adverse CV events, even after adjusting for coronary artery calcium score, Framingham Risk Score and BMI (64).

\section{GENERAL CONSIDERATIONS REGARDING CARDIOVASCULAR DISEASE IN FATTY LIVER DISEASE}

Several CV complications have been found to be significantly associated with FLD. Figure 2 describes the common CV complications that current studies have demonstrated to be associated with FLD including CAD, subclinical atherosclerotic risk, structural and functional cardiac modifications in addition to cardiac arrhythmias and conduction defects. These CV complications will be further discussed in details in Table 5 and the following sections.

It is challenging to assess the role that FLD plays in increasing CVD due to the common risk factors present in both pathologies. Several epidemiological studies demonstrated an increased incidence of adverse CV events in patients with FLD in comparison with the general population $(7,37)$. Söderberg et al. conducted a study with a 28 year follow up for patients with liver biopsy performed due to elevated liver function tests which demonstrated that patients with NAFLD presented with an increased total mortality rate compared to a matched reference population, whereas CVD was the main cause of death, exceeding cancer and liver related mortality (7).

On the other hand in regard to ALD, several studies demonstrated a U- or J- shaped association between moderate alcohol consumption with 1-2 drinks per day for men and 1 per day for women and cardiovascular benefits such as lower incidence of cardiovascular death and non-fatal myocardial infarction (65). However, alcoholic hyperlipidemia, associated with its thrombogenic, pro-inflammatory and pro-coagulative effects, is a definite CV risk factor in drinkers $(9,66)$. Currently, evidence is not sufficient to support the recommendation of alcohol use as a protective factor for adverse CV events.

\section{CARDIOVASCULAR DISEASE IN FATTY LIVER DISEASE \\ Coronary Artery Disease in Fatty Liver Disease}

Several studies evaluated the association between FLD and CAD. Most results demonstrated a significantly increased coronary atherosclerotic risk in the presence of FLD. Coronary artery calcification is an independent marker for adverse CV events resulting in a reduction in the vascular compliance, impaired myocardial perfusion and atherosclerotic extent, leading to an increased risk for developing CAD, as well as abnormal vasomotor responses and increased risk of long-term mortality $(67,68)$. Most published studies in the current literature assessed CAD risk using multiple detector computed tomography and by calculating the coronary artery calcium (CAC) score which is an appropriate method to evaluate asymptomatic subjects with an intermediate CV risk. On the other hand, fatty liver disease was mainly diagnosed using ultrasound.

Chang et al. conducted a recent cross-sectional study assessing the association of CAC score with FLD of alcoholic and non-alcoholic etiology on 105,328 subjects (69). The study demonstrated that both ALD and NAFLD were associated with an increased CAC score. Moreover, they also found that IR index was demonstrated to be a robust and independent predictor of CAC score, even after controlling for traditional CV risk factors, MetS, and C-reactive protein (CRP). Furthermore, a cross-sectional study on 250 subjects from the prospective population of Rancho Bernardo Study involving mainly white adults in suburban Southern California, conducted by Kim et al. demonstrated that although NAFLD was associated strongly with 


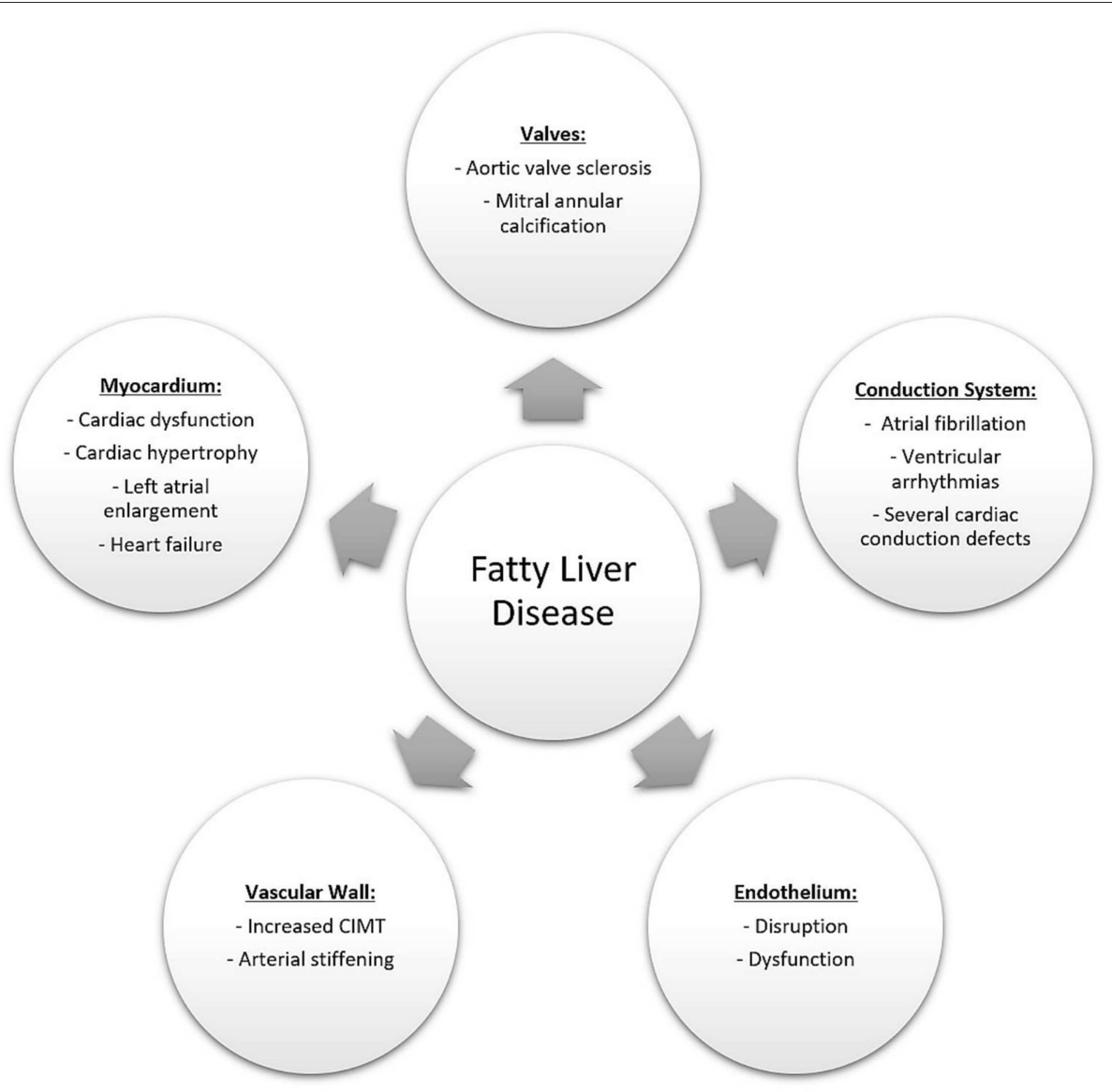

FIGURE 2 | Cardiovascular adverse events associated with fatty liver disease. These can include vascular involvement leading to an increased risk of coronary artery atherosclerosis, ischemic heart disease and an increased carotid intima media thickness. Other complications may include anatomical alterations such as valvular calcifications, functional alterations such as diastolic dysfunction as well as conduction system abnormalities leading to an increased risk of atrial and ventricular arrhythmias.

TABLE 5 | Cardiovascular complications in fatty liver disease and the common assessment methods.

\begin{tabular}{|c|c|}
\hline $\begin{array}{l}\text { Cardiovascular } \\
\text { complications in } \\
\text { fatty liver disease }\end{array}$ & Common methods of assessment \\
\hline Coronary artery disease & $\begin{array}{l}\text { Increased coronary artery calcium score-Multiple } \\
\text { detector computed tomography }\end{array}$ \\
\hline Carotid disease & $\begin{array}{l}\text { Increased carotid intima media thickness and presence } \\
\text { of carotid plaques - Carotid ultrasound }\end{array}$ \\
\hline Structural alterations & $\begin{array}{l}\text { Increased left ventricular mass index, interatrial } \\
\text { thickness, left atrial stiffness - Transthoracic } \\
\text { echocardiography }\end{array}$ \\
\hline Epicardial Fat & $\begin{array}{l}\text { Increased epicardial fat thickness } \\
\text { measurements - Transthoracic echocardiography }\end{array}$ \\
\hline Valvular calcifications & $\begin{array}{l}\text { Aortic-valve sclerosis and mitral annular } \\
\text { calcification-Transthoracic echocardiography }\end{array}$ \\
\hline Functional alterations & Diastolic dysfunction - Transthoracic echocardiography \\
\hline Arrythmias & $\begin{array}{l}\text { Atrial fibrillation, ventricular } \\
\text { arrhythmias - Electrocardiogram }\end{array}$ \\
\hline Conduction alterations & $\begin{array}{l}\text { Atrioventricular blocks, bundle branch } \\
\text { blocks-Electrocardiogram }\end{array}$ \\
\hline QTc interval & Prolonged QTc interval-Electrocardiogram \\
\hline
\end{tabular}

CAC, it was not found to be an independent factor for coronary atherosclerosis in postmenopausal women (70).

Wolff et al. assessed 2,351 subjects from the population-based Rotterdam Study and demonstrated that a proportional increase in liver fat is associated with an increase in EFT as well CAC independently from traditional CV risk factors (71). On the other hand, Kim et al. conducted a cross-sectional study on 2,238 individuals and reported that although CAC was associated with an increase in both EFT and liver fat, EFT was associated with CAC more strongly compared to NAFLD (72).

Moreover, a cross-sectional study conducted by Jacobs et al. involving 250 subjects mentioned that although elderly subjects had a lower prevalence of NAFLD, they still presented with an increased CAC score and visceral adipose tissue (VAT) (73). Lee et al. studied 21,335 subjects enrolled in a screening program demonstrating that NAFLD was more significantly associated with CAC compared to abdominal obesity (74) while another study involving 2,424 individuals from the Coronary Artery Risk Development in Young Adults study by VanWagner et al. suggested that obesity attenuates the association between NAFLD and subclinical atherosclerosis (75). 
Another cross-sectional study aiming to examine the relationship between liver fat and serum alanine transaminase (ALT) with coronary calcification in 1,218 subjects conducted by Jung et al. mentioned that subjects with both hepatic steatosis and elevated levels of ALT were found to be associated with a higher CAC score (76).

A strong association between NAFLD and prevalence of significant CAD determined by coronary angiography has also been consistently reported, albeit with variable thresholds of significant CAD between studies (37, 77-79). A study conducted by You et al. involving 285 asymptomatic individuals not known to have chronic liver and ischemic heart diseases reported that a higher CAC score was independently associated with liver stiffness values evaluated using transient elastography in patients with NAFLD (80).

\section{Carotid Disease in Fatty Liver Disease}

Carotid intima media thickness (CIMT) is independently associated with FLD, subclinical atherosclerosis, myocardial infarction and stroke (81). CIMT measurement and plaque burden by ultrasound can be used to screen asymptomatic individuals as it is a well-validated and widely accepted screening tool to predict CVD $(82,83)$.

A meta-analysis including 27 studies concluded that NAFLD was independently associated with subclinical atherosclerosis even after adjusting for traditional risk factors such as age, sex, BMI, smoking, LDL cholesterol, insulin resistance and MetS (84). Furthermore, studies reported that carotid plaques were present more frequently in NAFLD patients $(85,86)$.

Moreover, Kim et al. studied the association of atherosclerotic disease in FLD in relation to gender differences and concluded that males had a higher prevalence of FLD, carotid plaque and increased CIMT values compared to females (87). MartinezAlvarado Mdel et al. suggested that IR could be a mediator of metabolic abnormalities and subclinical atherosclerosis in females (88). A recent study conducted on 1,007 postmenopausal women by $\mathrm{Li}$ et al. reported that NAFLD was correlated with an elevated arterial stiffness risk in postmenopausal women, independent of the presence of MetS (89).

While Petit et al. reported in their study involving 102 type 2 diabetic patients that hepatic steatosis was not linked with increased risk of CVD (90), a more recent cross-sectional study conducted by Nahandi et al. on 151 subjects demonstrated a strong association between NAFLD and atherosclerosis independent of diabetes mellitus, while NAFLD severity and increased liver function tests showed an effect upon the atherosclerotic severity (91).

The severity of histological features of NAFLD were also found to be associated with increasing CIMT $(92,93)$. Bhatia et al. in a pre-sub study of WELCOME trial reported that a NAFLD severity improvement assessed using magnetic resonance spectroscopy and hepatic necro-inflammatory marker serum cytokeratin-18 was correlated with a reduced CIMT progression (94). According to Targher et al. the relationship associating NAFLD and subclinical CVD is mediated by visceral fat that was assessed by abdominal computed tomography (95).
Several laboratory tests were suggested to be associating hepatic steatosis with an increased risk for subclinical atherosclerosis. Arnic et al. suggested that gammaglutamyltransferase (GGT) and ALT may play a predictive value for CIMT in NASH patients (96). McKimmie et al. suggested in the diabetic heart study that the correlation between hepatic steatosis and CVD may just be an epiphenomenon although hepatic steatosis was demonstrated to be correlated with dyslipidemia (97).

On the other hand, several studies demonstrated a relationship between ALD and an increased CIMT (98). $\mathrm{Qu}$ et al. conducted a cross-sectional study on 152 subjects and assessed the association between ALD and CIMT (99). They concluded that ALD may not only lead to an increased CIMT, but it can also promote the premature occurrence of CIMT thickening. Moreover, a recent cross-sectional study conducted on 160 subjects suggested a "double hit phenomenon" as ALD coupled with $\mathrm{H}$. pylori infection can lead to an important CIMT thickening (100).

\section{Cardiac Structural and Functional Alterations in Fatty Liver Disease}

The current literature provides convincing evidence relating FLD with several functional and structural myocardial modifications in the presence or absence of other coexisting features of MetS. Most studies reported a significant correlation associating NAFLD with left ventricular (LV) functional and structural modifications even after adjusting for the commonly associated cardiometabolic risk factors.

In patients with NAFLD without morbid obesity, hypertension and diabetes, the presence of mildly altered LV geometry and early features of LV diastolic dysfunction can be present. The consistent finding of subclinical cardiac dysfunction in an asymptomatic population with NAFLD is not surprising, given that LV dysfunction and LV mass are strongly correlated with IR, as well as subsequent prognosis. Azzam et al. mentioned the existence of a strong positive correlation relating the amount of liver fat with diastolic dysfunction and IR, the only independent parameters found to be associated with NAFLD in their study (101). In patient with diabetes and NAFLD, early features of LV diastolic dysfunction may be detected.

Liver fibrosis assessed histologically was demonstrated to be related to several cardiac parameters assessed by echocardiography. A study assessing the severity of liver fibrosis and cardiac complications conducted on 147 biopsy proven NAFLD patients by Petta et al. reported that several cardiac structural modifications such as diastolic posterior-wall thickness, LV mass, relative wall thickness, left atrial volume as well as LV diastolic dysfunction, ejection fraction, lower lateral tissue doppler imaging peak early diastolic mitral annulus velocity (E') and the ratio of peak velocity blood flow from gravity in early diastole (E wave) to peak velocity flow in late diastole caused by atrial contraction (A wave) also known as the E/A ratio were all associated with severe liver fibrosis (102). Histological liver severity was also demonstrated to be the only independent predictor of impaired coronary flow reserve in a cross-sectional 
study involving 136 individuals reported by Yilmaz et al. evaluating the integrity of the coronary microvascular circulation (103). They concluded that a lower coronary flow reserve was present in NAFLD patients compared to healthy controls, even after adjusting for obesity, traditional CV risk factors and MetS.

A recent study conducted by Mahfouz et al. on 260 individuals suggested that increased interatrial thickness and left atrial stiffness index found in NAFLD patients could explain the cause behind an increased incidence of atrial fibrillation (AF) (104).

Several articles described a significant association between EFT and NAFLD. Oguz et al. conducted a cross-sectional study concluding that EFT and osteoprotegerin level were increased while aortic flow propagation velocity was decreased in patients with NAFLD (105). Another study involving 868 subjects from the PLIC Study conducted by Baraghetti et al. reported that hepatic steatosis and EFT were related to an increased incidence of extra-cardiac plaques (106). A study conducted on 100 biopsy proven NAFLD and 50 age and sex matched control subjects by Sunbul et al. reported that NAFLD was correlated with an increased arterial stiffness assessed using pulse wave velocity and augmentation index reflecting both the severity of liver fibrosis and increased EFT values (107). On the other hand, Psychari et al. reported an observational cross-sectional study on 105 patients demonstrating that EFT was not significantly associated with NAFLD per se, but to diabetes and inflammation (108).

Moreover, cardiac structural and functional alterations were also demonstrated in patients with ALD. Patients with alcoholic liver cirrhosis can present with cirrhotic cardiomyopathy representing an alteration in cardiac function in the absence of a clear underlying CV cause. Alcoholic cirrhosis exerts an important influence on the CV system and hemodynamics of the heart leading to an increased heart rate and cardiac output, in addition to a decreased systemic vascular resistance, arterial pressure, and plasma volume expansion. Alcoholic cardiomyopathy is demonstrated to present with dilated LV, increased LV mass and a normal or decreased LV wall thickness in addition to systolic and diastolic dysfunction although it starts primarily as an altered diastolic function without abnormal changes in the systolic function at rest $(109,110)$.

\section{Heart Valve Calcification in Fatty Liver Disease}

Aortic-valve sclerosis and mitral annular calcification, both associated with an increased risk of cardiac arrhythmias, all cause and CV mortality rates, are frequently found on echocardiography in elderly subjects being present in up to $20 \%$ of adults older than 65 years old (111-113).

Several studies demonstrated an association between FLD and calcification of the aortic and mitral heart valves. A cross-sectional study conducted by Markus et al. reported that hepatic steatosis was associated with $32 \%$ higher odds for developing aortic valve sclerosis in comparison to subjects without hepatic steatosis after adjusting for high-sensitive Creactive protein (hs- CRP), serum ferritin levels, and white blood cells (114). Moreover, a study conducted on 180 type 2 diabetics by Bonapace et al. demonstrated for the first time a positive and independent association between NAFLD and aortic valve sclerosis in diabetic patients even after adjusting for age, sex, duration of diabetes, diabetes treatment, BMI, smoking, alcohol consumption, hypertension, dyslipidemia, glycated hemoglobin (HbAlc) and estimated glomerular filtration rate (115). Furthermore, Mantovani et al. reported that NAFLD was found to be an independent predictor of cardiac calcification in both the aortic and mitral valves in patients with type 2 diabetes, even after performing adjustments (116).

Till present, several studies demonstrated an association between NAFLD and the presence of aortic and mitral valves calcification mainly in diabetic patients while this association remains to be assessed in non-diabetics with FLD. Moreover, the association between ALD and heart valve calcification remains to be studied.

\section{Cardiac Arrythmias and Conduction Abnormalities in Fatty Liver Disease}

The association between FLD and risk of cardiac arrhythmias, as well as related conduction abnormalities has attracted scientific interest lately. Multiple studies assessed the relationship between FLD with several electrocardiogram findings and demonstrated the presence of an increased risk of AF, prolonged QTc interval, bundle branch and atrioventricular blocks. Moreover, diabetic patients with NAFLD were also demonstrated to present with an increased risk for developing ventricular arrhythmias.

The most common type of sustained arrhythmia is AF being a major health problem due to increased morbidity and mortality. Multiple studies assessed the relationship between FLD and AF. A recent meta-analysis that evaluated 9 cross-sectional and longitudinal studies with a total population of 364,919 subjects reported that NAFLD was correlated with an increased risk of AF in middle-aged and elderly subjects and especially in type 2 diabetics (117). Zhang et al. conducted a cross-sectional study on 1,688 subjects, demonstrating that elderly subjects with NAFLD presented with a significant prevalence of AF, even after adjusting for age, gender, systolic blood pressure, fasting plasma glucose, GGT, HDL cholesterol, triglycerides, total cholesterol and albumin (118). On the other hand, Markus et al. performed a population-based Study of Health in Pomerania on 3,090 subjects and concluded that moderate elevation in serum liver enzymes and not hepatic steatosis diagnosed using ultrasound were correlated with higher AF prevalence rates (119). They suggested that a possible pathogenic mechanism behind this correlation might be attributed to elevated levels of pro-inflammatory, procoagulant and profibronogenic factors associated with increased levels of serum liver enzymes causing structural and electrical alterations of the atrium leading to a higher risk of AF. Moreover, Montovani suggested that hyperuricemia might be playing a mechanistic role in the association between NAFLD and AF (120).

Another retrospective study involving 330 type 2 diabetics conducted by Montovani et al. described a significant association presented for the first time correlating NAFLD with an increased prevalence of $>30 \mathrm{PVCs} / \mathrm{h}$, non-sustained ventricular tachycardia or both (121). A 3.5-fold increase risk of ventricular 
arrhythmias was found in NAFLD patients independent of age, sex, BMI, smoking, hypertension, ischemic heart disease, valvular heart disease, chronic kidney disease, chronic obstructive pulmonary disease, serum GGT levels, medication use, and left ventricular ejection fraction.

Another known risk factor for sudden cardiac death is a prolonged QT interval that was demonstrated to be present in patients with FLD. Hung et al. conducted a cross-sectional analysis on 31,116 subjects demonstrating an increased risk for QTc interval prolongation in both diabetic and non-diabetic patients with NAFLD even after adjusting for known factors associated with the QTc interval (122).

A hospital-based cohort of 751 patients with type 2 diabetes conducted by Montovani et al. demonstrated that subjects with NAFLD presented with a significantly increased prevalence of persistent heart block defined by the presence of at least one block among first-degree atrioventricular block, second-degree atrioventricular block, third-degree atrioventricular block, left bundle branch block, right bundle branch block, left anterior hemi-block or left posterior hemi-block compared to subjects without NAFLD being even stronger among subjects with a higher FIB-4 score (123). Furthermore, a threefold increased risk of prevalent heart block was found to be in NAFLD patients after adjusting for age, sex, hypertension, prior ischemic heart disease, HbA1c, microvascular complication status, use of medications and other potentially confounding factors. Iscen reported that young, healthy subjects with right bundle branch block presented with an increased risk of having NAFLD (124).

Vagal reactivation can be evaluated using the heart rate recovery after performing exercise. Abnormal results present an independent prognostic factor for $\mathrm{CV}$ and all-cause mortality. Ozveren et al. reported that NAFLD patients have an altered heart rate recovery index (125).

\section{FATTY LIVER DISEASE TREATMENT AND CARDIOVASCULAR RISK PREVENTION}

Each patient with FLD should be evaluated and managed accordingly. Possible management methods include nonpharmacological strategies, pharmacological therapies as well as surgical management as described in Figure 3.

\section{Non-pharmacological Methods}

Non-pharmacological interventions are the current cornerstone of the management of FLD. Current management of FLD is achieved through several methods including lifestyle changes leading to weight loss and obesity reduction, in addition to the prevention of MetS by controlling cardiometabolic risk factors involved as well as improving NASH in order to prevent the progression of liver fibrosis to cirrhosis and eventually HCC. Studies demonstrated that individualized therapy and lifestyle changes in FLD patients not only improve liver enzyme levels as well as lead to a reduction in hepatic steatosis, injury and fibrosis, but also decrease the risk of developing several complications including CVD, type 2 diabetes mellitus and several types of cancers (16). FLD patients can also decrease their hepatic CV related risk by decreasing their weight and preventing the occurrence of MetS.

\section{Dietary Changes}

Despite multiple studies discussing different dietary plans recommended for FLD patients, the best dietary plan remains to be known (126). Patients who maintain a long-term calorie restricted diet for 1 year or more were found to have an improvement in hepatic steatosis and decreased CV risk (127, 128). FLD patients are recommended to restrict foods which contain fructose, saturated fats, simple carbohydrates and sugar containing drinks (129) while substituting these with a low fat and high carbohydrate diet in addition to increasing fruits and vegetables intake (130). It has been demonstrated that non-diabetic patients who consume a Mediterranean diet containing high levels of monounsaturated fatty acids presented with an improvement in their hepatic steatosis and insulin sensitivity (131). Furthermore, a recently published metaanalysis mentioned that coffee use may slow down and decrease the risk of liver fibrosis (132). Moreover, alcohol restriction and smoking cessation are essential and also recommended (133).

\section{Weight Control}

Patients with FLD can achieve significant improvement and prevent further liver damage through body weight reduction of $5 \%$ or more, regardless of the method used for weight loss such as a low-calorie diet, physical activity or bariatric surgery, with a better outcome in patients loosing $10 \%$ or more of their body weight $(134,135)$. Moreover, several structural and functional cardiac abnormalities seem to be reversible in the presence of a sustained body weight reduction (136-138). Nonetheless, a paradoxical relationship has been demonstrated associating increased BMI with a better prognosis in patients with clinically symptomatic heart failure $(139,140)$. This can be explained by a potentially cardioprotective effect found in obese patients exerted through a reduced neurohormonal system activation, improved protection toward endotoxin and pro-inflammatory cytokines as well as an increased metabolic and nutritional reserve (140). Accordingly, seeking weight loss in patients with FLD and an associated advanced cardiac dysfunction should be cautiously performed, as well as point out the importance of early stage lifestyle changes in order to prevent complications (16).

\section{Exercise}

Lack of physical activity is a known risk factor associated with FLD (141, 142). Exercise decreases insulin resistance, a known CV risk factor, through increasing insulin sensitivity at the level of the skeletal muscles, as well as improving hepatic steatosis $(143,144)$. Moreover, physical activity results in an increased energy expenditure. This can lead to weight loss, as well as decreased intrahepatic triglyceride content (145). Studies demonstrated that resistance, moderate and high intensity training can result in several beneficial hepatic effects such as releasing myokines and other mediators, which act as protective factors in FLD, regardless of weight loss associated with exercise (146). Furthermore, beneficial effects of physical exercise have been demonstrated in FLD patients with $\operatorname{CVD}(147,148)$. 


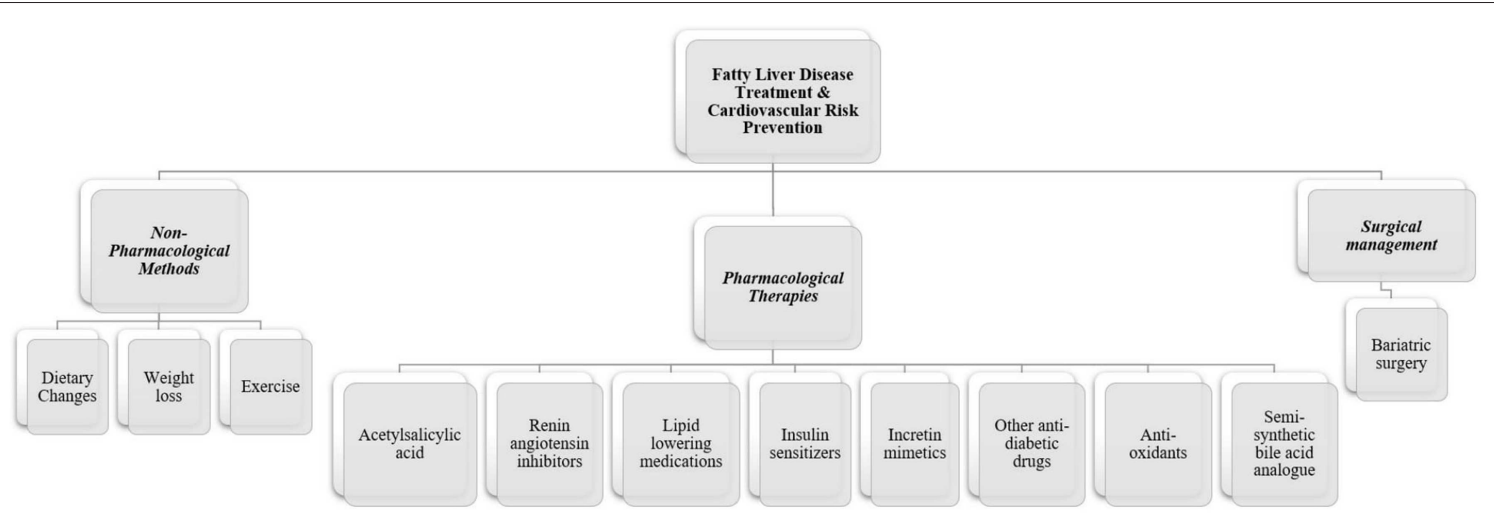

FIGURE 3 | Management strategies in fatty liver disease with cardiovascular risk reduction. Management of fatty liver disease should be individualized to each patient accordingly. Non-pharmacological interventions are essential in the management of fatty liver disease through several lifestyle changes. Currently, no specific pharmacological therapies are approved for NAFLD or NASH. However, several therapeutic drugs were studied and demonstrated positive results in improving hepatic steatosis and liver enzymes as well as decreasing cardiovascular risk, while other drugs are showing promising results in undergoing late phase clinical trials. Surgical management is also possible in specific indicated cases.

Nonetheless, the majority of FLD patients do not succeed to reach their target weight loss goals or to maintain these results for long-term (149).

\section{Pharmacological Therapies}

At the moment, there are no specific approved pharmacological therapies for NAFLD or NASH (150). Despite the absence of firm recommendations for how to manage $\mathrm{NASH}$, several pharmacological therapies are currently available including insulin sensitizers, antioxidants, lipid-lowering agents, incretinbased drugs and weight loss medication (10). Due to the fact that no specific drug is currently approved for treating NAFLD, a quick and rapid evolution in scientific research is under process in order to discover possible pharmacological therapies for treating this pathology.

\section{Acetylsalicylic Acid}

Despite the controversy regarding the benefits of acetylsalicylic acid (ASA) use for primary CVD prevention which was reported in a recent meta-analysis and systematic review including 13 trials and randomizing 164,225 participants demonstrating that subjects without known CVD that received daily aspirin had a lower risk of adverse $\mathrm{CV}$ events but with the cost of increasing the risk of major bleeding (151), it is demonstrated to be beneficial and is indicated for secondary prevention in patients with symptomatic atherosclerotic disease. On the other hand, much of the current literature assessing the effect of ASA in FLD has been limited to cross-sectional studies demonstrating that subjects receiving ASA have reduced liver fibrosis indexes levels (152). Moreover, a recent prospective cohort study performed on 361 adults with biopsy-confirmed NAFLD out of which 151 subjects were receiving daily ASA demonstrated for the first time prospectively that daily ASA use in NAFLD was associated with less severe histologic features on biopsy of NAFLD and NASH, in addition to a lower progression risk to advanced fibrosis with the most benefit found in subjects who received daily ASA for $\geq 4$ years (153). Therefore, due to all the robust literature demonstrating that FLD is associated with an increased CV risk, ASA use in FLD patients seems an important consideration in clinical practice.

\section{Renin Angiotensin Inhibitors}

Patients with FLD usually present with an increased prevalence of several risk factors such as hypertension, type 2 diabetes mellitus and kidney disease. This indicates that the activation of the renin angiotensin system (RAS) might be playing a role leading to liver fibrosis. Several clinical trials studied the effects of antihypertensive agents in FLD patients demonstrating that hypertensive patients who received RAS antagonists had reduced levels of FLD progression (154-157). A recent observational study conducted on 118 patients with NAFLD who were followed for a median of 36 months demonstrated that diabetic patients using of RAS inhibitors such as angiotensin converting enzyme inhibitors or angiotensin receptor blockers were associated with reduced histological fibrosis progression rates (158). Nevertheless, randomized clinical trials are required to confirm this effect.

\section{Lipid Lowering Medications}

Despite the controversial evidence linking the use of statins and ezetimibe with a decreased risk of FLD, mainly due to grossly underpowered studies, mainly observational and not experimental studies, in addition to the lack of histological assessment of liver injury severity (159-161), they remain a key therapy for reducing the risk of adverse CV events as well as mortality $(162,163)$. Current studies reported that statins use was associated with a reduced CV risk $(164,165)$ and improved liver enzymes as demonstrated in a post-hoc analysis of the Greek Atorvastatin and Coronary Heart Disease Evaluation (GREACE) study (166). Statin therapy shouldn't be precluded in subjects with FLD, high CV risk and elevated aminotransferases as current evidence does not prove liver damage in this context (167). 
Moreover, high dose omega-3 fatty acids were not found to be associated with improved histological features in NASH $(168,169)$, although some evidence suggests an improvement in dyslipidemia and a reduction in liver enzymes (170).

\section{Insulin Sensitizers, Incretin Mimetics, and Other Anti-diabetic Drugs}

Insulin resistance is significantly involved in the pathogenesis of FLD. Several therapeutic agents that are currently approved for treating type 2 diabetes mellitus have been evaluated for possible positive outcomes related to liver injury in patients with FLD.

Metformin remains the cornerstone therapy for type 2 diabetes mellitus patients. Despite the fact that metformin use in NAFLD and NASH patients was associated with improved insulin resistance and reduced aminotransferase levels (171), it failed to improve liver injury evaluated histologically or NASH reported in a meta-analysis $(134,156)$. Nevertheless, cross-sectional studies demonstrated that metformin use may protect against the progression to hepatocellular carcinoma (172), as well as a reduced mortality rate in cirrhotic patients (173). Therefore, the use of metformin should be considered in type 2 diabetic patients and FLD, unless a contraindication such as severe hepatic or renal failure is present. Moreover, a randomized double-blind placebo controlled trial performed on 68 patients with prediabetes and/or insulin resistance demonstrated that metformin treatment was significantly associated with reduced LV mass index, office systolic BP, reduced body weight and oxidative stress explaining that metformin exerts a cardioprotective effect and suggesting the possibility of metformin use in CAD patients who are non-diabetics (174).

On the other hand, alternative therapeutic drugs mainly targeting insulin resistance seem to be associated with better hepatic histological outcomes in NASH. Examples include pioglitazone, a peroxisome proliferator- activated receptor- $\gamma$ $(\operatorname{PPAR} \gamma)$ agonist $(175,176)$ and liraglutide, a glucagon- like peptide 1 (GLP1) agonist (177). The PIVENS (Pioglitazone vs. Vitamin E vs. Placebo for the Treatment of Non-diabetic Patients with Non-alcoholic Steatohepatitis) trial demonstrated that despite the histological improvement of NASH except fibrosis associated with Pioglitazone, vitamin E, a lipophilic antioxidant vitamin $\mathrm{E}$ was reported to be more effective in improving and resolving inflammation (175). However, a recently published study suggests that treatment with Pioglitazone for a long-term can lead to a reduction in liver damage as well as fibrosis (176). The decision of starting treatment with Pioglitazone should be considered for each patient individually based on risks and benefits due to several side effects such as causing or exacerbating congestive heart failure in some patients (178). Moreover, the GLP-1 agonist, liraglutide, was evaluated in several studies. The phase II LEAN study demonstrated a better NASH resolution rate in addition to a reduced liver fibrosis progression and weight loss (177). The LIRA-NAFLD study demonstrated that uncontrolled type 2 diabetic patients were able to achieve a reduction in their liver fat content of an average $31 \%$ after receiving liraglutide 1.2 mg/day for 6 months (179). The LEADER (Liraglutide Effect and Action in Diabetes: Evaluation of Cardiovascular Outcome Results) trial reported that type 2 diabetic patients that received liraglutide treatment presented with reduced rates of fatal and non-fatal adverse CV events as well as death from any cause compared to the placebo group (180).

Recent studies including randomized controlled clinical trials demonstrated that sodium-glucose cotransporter type-2 (SGLT2) inhibitors can improve hepatic steatosis and serum liver enzymes in type 2 diabetic patients with NAFLD as well as exert the already well-known CV protective effects (181). On the other hand, a study conducted on diabetic patients demonstrated that Sitagliptin, the DPP-4 inhibitor, was not to be effective in hepatic fat content reduction (182).

Furthermore, other drugs with an insulin sensitizing effect are currently under evaluation, such as elafibranor, a PPAR $\alpha$ PPAR $\delta$ agonist, evaluated in phase IIB randomized placebocontrolled GOLDEN 505 trial (183) where is was demonstrated to improve serum lipid levels and liver enzymes. Currently, the overall benefit is under evaluation in the phase III RESOLVE-IT trial. Moreover, other promising novel agents such as IVA337, a PPAR $\alpha$-PPAR $\delta$-PPAR $\gamma$ agonist and saroglitazar, a PPAR $\alpha-$ $\operatorname{PPAR} \gamma$ agonist are currently being evaluated in randomized controlled clinical trials in patients with FLD in order to assess their efficacy as treatment for NASH in late phase clinical trials (184). The CV outcomes and benefits related to the use of these drugs remain to be assessed.

\section{Semi-Synthetic Bile Acid Analog}

Obeticholic acid, a potent agonist of Farnesoid X Receptor (FXR) with activity against hepatic fat accumulation, inflammation and fibrosis, has been studied in the phase IIb Farnesoid X Receptor Ligand Obeticholic Acid in NASH Treatment (FLINT) trial in non-cirrhotic NASH patients with results demonstrating an improvement in NASH histology with the main safety signals being elevated LDL levels despite concomitant statin use, possible worsening of insulin resistance, as well as pruritus (185). The phase III REGENERATE trial is being conducted which will also include CV risk assessment.

\section{Surgical Management}

Bariatric surgery can be useful in a specific group of patients with fatty liver disease that are unresponsive to several trials of lifestyle changes as well as intensive pharmacotherapy as it can improve NASH histologically, lead to weight loss and reduce obesity-related metabolic complications, while demonstrating long-term stable results $(10,186)$. However, bariatric surgery remains an invasive procedure with possible complications and increased costs, limiting its assessment as a primary management strategy in NASH patients, currently being limited mainly to manage obesity.

\section{CONCLUSIONS}

This review supports the existence of a strong association between the presence and severity of FLD leading to several $\mathrm{CV}$ adverse events such as CAD, subclinical atherosclerosis risk, structural and functional cardiac modifications in addition to cardiac arrhythmias and conduction defects. Currently, the most common cause of death in NAFLD is CVD. 
Despite the current evidence supporting the association between FLD and an increased CV risk, the exact mechanisms attributing to this relationship remain uncertain. Therefore, further research is required in order to discover the exact pathophysiological mechanisms behind this association to prevent further complications.

The current data emphasizes how FLD is a multisystem disease by presenting adverse effects on the liver in addition to extrahepatic manifestations including cardiac and vascular complications. This also entails that FLD patients with a high CVD risk should undergo a careful CV screening regardless of the presence of the traditional CV risk factors as per the current practice recommendations by the European Association for the Study of the Liver (EASL), European Association for the Study of Diabetes (EASD) and European Association for the Study of Obesity (EASO) as well as the American Association for the Study of Liver Diseases.

Accordingly, a multidisciplinary patient centered, personalized medicine approach is required to provide FLD

\section{REFERENCES}

1. Go AS, Mozaffarian D, Roger VL, Benjamin EJ, Berry JD, Blaha MJ, et al. Heart disease and stroke statistics-2014 update: a report from the American Heart Association. Circulation. (2014) 129:e28-92. doi: 10.1161/01.cir.0000441139.02102.80

2. Charlton MR, Burns JM, Pedersen RA, Watt KD, Heimbach JK, Dierkhising RA. Frequency and outcomes of liver transplantation for nonalcoholic steatohepatitis in the United States. Gastroenterology. (2011) 141:1249-53. doi: 10.1053/j.gastro.2011.06.061

3. Mathurin P, Bataller R. Trends in the management and burden of alcoholic liver disease. J Hepatol. (2015) 62:S38-46. doi: 10.1016/j.jhep.2015.03.006

4. Younossi ZM, Stepanova M, Afendy M, Fang Y, Younossi Y, Mir H, et al. Changes in the prevalence of the most common causes of chronic liver diseases in the United States from 1988 to 2008. Clin Gastroenterol Hepatol. (2011) 9:524-530.e521; quiz e560. doi: 10.1016/j.cgh.201 1.03 .020

5. Younossi ZM, Koenig AB, Abdelatif D, Fazel Y, Henry L, Wymer M. Global epidemiology of nonalcoholic fatty liver disease-Meta-analytic assessment of prevalence, incidence, and outcomes. Hepatology. (2016) 64:73-84. doi: $10.1002 /$ hep. 28431

6. Radu C, Grigorescu M, Crisan D, Lupsor M, Constantin D, Dina L. Prevalence and associated risk factors of non-alcoholic fatty liver disease in hospitalized patients. J Gastrointestin Liver Dis. (2008) 17:255-60. Available online at: http://www.jgld.ro/2008/3/1.html

7. Soderberg C, Stal P, Askling J, Glaumann H, Lindberg G, Marmur J, et al. Decreased survival of subjects with elevated liver function tests during a 28-year follow-up. Hepatology. (2010) 51:595-602. doi: 10.1002/hep.23314

8. Ekstedt M, Hagstrom H, Nasr P, Fredrikson M, Stal P, Kechagias S, et al. Fibrosis stage is the strongest predictor for disease-specific mortality in NAFLD after up to 33 years of follow-up. Hepatology. (2015) 61:1547-54. doi: $10.1002 /$ hep. 27368

9. Brinton EA. Effects of ethanol intake on lipoproteins and atherosclerosis. Curr Opin Lipidol. (2010) 21:346-51. doi: 10.1097/MOL.0b013e32833c1f41

10. Sporea I, Popescu A, Dumitrascu D, Brisc C, Nedelcu L, Trifan A, et al. Nonalcoholic fatty liver disease: status quo. J Gastrointestin Liver Dis. (2018) 27:439-48. doi: 10.15403/jgld.2014.1121.274.quo

11. Targher G, Day CP, Bonora E. Risk of cardiovascular disease in patients with nonalcoholic fatty liver disease. N Engl J Med. (2010) 363:1341-50. doi: 10.1056/NEJMra0912063

12. Dumitrascu DL, Neuman MG. Non-alcoholic fatty liver disease: an update on diagnosis. Clujul Med. (2018) 91:147-50. doi: 10.15386/cjmed-993 patients with the best management. Encouraging FLD patients to undergo early lifestyle changes such as weight loss, exercise and dietary changes is highly recommended. Other possible pharmacological therapies include anti-diabetic drugs such as metformin, SGLT2 inhibitors, PPAR $\gamma$ and GLP-1 agonists, lipid lowering medications mainly statins as well as renin angiotensin system inhibitors due to their effect in reducing cardiovascular risk especially in the presence of dyslipidemia, diabetes and hypertension. Surgical management remains of limited use due to its invasiveness, high costs and possible complications.

\section{AUTHOR CONTRIBUTIONS}

AI had the idea of this review, did the literature survey and wrote the manuscript. DD checked the literature survey, suggested methodology and contributed to the writing of the manuscript. All authors revised the final manuscript and approved the final version.

13. Macavei B, Baban A, Dumitrascu DL. Psychological factors associated with NAFLD/NASH: a systematic review. Eur Rev Med Pharmacol Sci. (2016) 20:5081-97. Available online at: https://www.europeanreview.org/ article/11915

14. Brunt EM, Janney CG, Dibisceglie AM, Neuschwander-Tetri B, Br B. Nonalcoholic steatohepatitis: a proposal for grading and staging the histological lesions. Am J Gastroenterol. (1999) 9:2476-4.

15. Brunt EM. Nonalcoholic steatohepatitis: definition and pathology. Semin Liver Dis. (2001) 21:3-16.

16. Chalasani N, Younossi Z. The diagnosis and management of nonalcoholic fatty liver disease: practice guidance from the American Association for the Study of Liver Diseases. (2018) 67:328-57. doi: 10.1002/hep.29367

17. Monsour HP, Jr, Frenette CT, Wyne K. Fatty liver: a link to cardiovascular disease-its natural history, pathogenesis, and treatment. Methodist Debakey Cardiovasc J. (2012) 8:21-25.

18. Burt Ad RM. Pathology of alcoholic liver disease. In: Bircher J, Benhamou JP, McIntyre N, Rizzetto M, Rodes J, editors. Oxford Textbook of Clinical Hepatology. Oxford: Oxford University Press (1999). pp. 1179-84.

19. Karl Seitz, H., Mueller, S., and Dancygier, H. Alcoholic liver disease. In: Clinical Hepatology: Principles and Practice of Hepatobiliary Diseases. Berlin; Heidelberg: Springer (2010). pp. 1111-1151. doi: 10.1007/978-3-642-04519-6_34

20. Alberti KG, Eckel RH, Grundy SM, Zimmet PZ, Cleeman JI, Donato KA, et al. Harmonizing the metabolic syndrome: a joint interim statement of the International Diabetes Federation Task Force on Epidemiology and Prevention; National Heart, Lung, and Blood Institute; American Heart Association; World Heart Federation; International Atherosclerosis Society; and International Association for the Study of Obesity. Circulation. (2009) 120:1640-5. doi: 10.1161/circulationaha.109.192644

21. Filipović B, Forbes A, Tepeš B, Dumitraşcu DL. Nonalcoholic fatty liver disease. Can J Gastroenterol Hepatol. (2018) 2018:2097435. doi: $10.1155 / 2018 / 2097435$

22. Kucukazman M, Ata N, Yavuz B, Dal K, Sen O, Deveci OS, et al. Evaluation of early atherosclerosis markers in patients with nonalcoholic fatty liver disease. Eur J Gastroenterol Hepatol. (2013) 25:147-51. doi: 10.1097/MEG.0b013e32835a58b1

23. Gastaldelli A, Kozakova M, Hojlund K, Flyvbjerg A, Favuzzi A, Mitrakou A, et al. Fatty liver is associated with insulin resistance, risk of coronary heart disease, and early atherosclerosis in a large European population. Hepatology. (2009) 49:1537-44. doi: 10.1002/hep.22845

24. Rocha R, Cotrim HP, Carvalho FM, Siqueira AC, Braga H, Freitas LA. Body mass index and waist circumference in non-alcoholic fatty liver 
disease. J Hum Nutr Diet. (2005) 18:365-70. doi: 10.1111/j.1365-277X.2005. 00634.x

25. Lu H, Liu H, Hu F, Zou L, Luo S, Sun L. Independent association between nonalcoholic fatty liver disease and cardiovascular disease: a systematic review and meta-analysis. Int J Endocrinol. (2013) 2013:124958. doi: $10.1155 / 2013 / 124958$

26. Chitturi S, Abeygunasekera S, Farrell GC, Holmes-Walker J, Hui JM, Fung $\mathrm{C}$, et al. NASH and insulin resistance: insulin hypersecretion and specific association with the insulin resistance syndrome. Hepatology. (2002) 35:3739. doi: 10.1053/jhep.2002.30692

27. Baliunas DO, Taylor BJ, Irving HEA. Alcohol as a risk factor for type 2 diabetes: a systematic review and meta-analysis. Diabet Care. (2009) 32:2123e2132. doi: $10.2337 / \mathrm{dc} 09-0227$

28. Garcia-Compean D, Jaquez-Quintana JO, Gonzalez-Gonzalez JA, Maldonado-Garza H. Liver cirrhosis and diabetes: risk factors, pathophysiology, clinical implications and management. World $J$ Gastroenterol. (2009). 15:280-8. doi: 10.3748/wjg.15.280

29. Pflaum T, Hausler T, Baumung C, Ackermann S, Kuballa T, Rehm J, et al. Carcinogenic compounds in alcoholic beverages: an update. Arch Toxicol. (2016) 90:2349-67. doi: 10.1007/s00204-016-1770-3

30. Chen C-J, Brown WM, Moomaw CJ, Langefeld CD, Osborne J, Worrall BB, et al. Alcohol use and risk of intracerebral hemorrhage. Neurology. (2017) 88:2043-51. doi: 10.1212/WNL.0000000000003952

31. Costa P, Grassi M, Iacoviello L, Zedde M, Marcheselli S, Silvestrelli G, et al. Alcohol intake and the risk of intracerebral hemorrhage in the elderly. MUCH-Italy. (2018) 91:e227-e235. doi: 10.1212/wnl.00000000000 05814

32. Gregor MF, Hotamisligil GS. Inflammatory mechanisms in obesity. Апnu Rev Immunol. (2011) 29:415-45. doi: 10.1146/annurevimmunol-031210-101322

33. Tilg $\mathrm{H}$, Moschen AR. Evolution of inflammation in nonalcoholic fatty liver disease: the multiple parallel hits hypothesis. Hepatology. (2010) 52:1836-46. doi: 10.1002/hep.24001

34. Liu YL, Reeves HL, Burt AD, Tiniakos D, Mcpherson S, Leathart JB, et al. TM6SF2 rs58542926 influences hepatic fibrosis progression in patients with non-alcoholic fatty liver disease. Nat Commun. (2014) 5:4309. doi: 10.1038/ncomms5309

35. Anstee QM, Day CP. The genetics of nonalcoholic fatty liver disease: spotlight on PNPLA3 and TM6SF2. Semin Liver Dis. (2015). 35:270-90. doi: $10.1055 / \mathrm{s}-0035-1562947$

36. Kahali B, Liu YL, Daly AK, Day CP, Anstee QM, Speliotes EK. TM6SF2: catch-22 in the fight against nonalcoholic fatty liver disease and cardiovascular disease? Gastroenterology. (2015) 148:679-84. doi: 10.1053/j.gastro.2015.01.038

37. Bhatia LS, Curzen NP, Calder PC, Byrne CD. Non-alcoholic fatty liver disease: a new and important cardiovascular risk factor? Eur Heart J. (2012) 33:1190-200. doi: 10.1093/eurheartj/ehr453

38. Francque SM, Van Der Graaff D, Kwanten WJ. Non-alcoholic fatty liver disease and cardiovascular risk: pathophysiological mechanisms and implications. J Hepatol. (2016) 65:425-43. doi: 10.1016/j.jhep.2016. 04.005

39. Cakir E, Ozbek M, Colak N, Cakal E, Delibaşi T. Is NAFLD an independent risk factor for increased IMT in T2DM? Minerva Endocrinol. (2012) 37:187-93. Available online at: https://www.minervamedica.it/en/ journals/minerva- endocrinologica/article.php?cod=R07Y2012N02A0187

40. Bhatia, L. S., Curzen, N. P., and Byrne, C. D. (2012). Nonalcoholic fatty liver disease and vascular risk. Curr. Opin. Cardiol. 27, 420-428. doi: 10.1097/HCO.0b013e328354829c

41. Fabbrini E, Magkos F, Mohammed BS, Pietka T, Abumrad NA, Patterson BW, et al. Intrahepatic fat, not visceral fat, is linked with metabolic complications of obesity. Proc Natl Acad Sci USA. (2009) 106:15430-5. doi: $10.1073 /$ pnas. 0904944106

42. Neuschwander-Tetri BA. Hepatic lipotoxicity and the pathogenesis of nonalcoholic steatohepatitis: the central role of nontriglyceride fatty acid metabolites. Hepatology. (2010) 52:774-88. doi: 10.1002/hep.23719

43. Fabbrini E, Sullivan S, Klein S. Obesity and nonalcoholic fatty liver disease: biochemical, metabolic, and clinical implications. Hepatology. (2010) 51:679-89. doi: 10.1002/hep.23280
44. Gaziano JM, Hennekens CH, O'donnell CJ, Breslow JL, Buring JE. Fasting triglycerides, high-density lipoprotein, and risk of myocardial infarction. Circulation. (1997) 96:2520-25.

45. Hurjui DM, Nita O, Graur LI, Mihalache L, Popescu DS, Hutanasu IC, et al. Non-alcoholic fatty liver disease is associated with cardiovascular risk factors of metabolic syndrome. Rev Med Chir Soc Med Nat Iasi. (2012) 116:692-9.

46. Colak Y, Senates E, Yesil A, Yilmaz Y, Ozturk O, Doganay L, et al. Assessment of endothelial function in patients with nonalcoholic fatty liver disease. Endocrine. (2013) 43:100-7. doi: 10.1007/s12020-012-9712-1

47. Feitosa MF, Reiner AP, Wojczynski MK, Graff M, North KE, Carr JJ, et al. Sex-influenced association of nonalcoholic fatty liver disease with coronary heart disease. Atherosclerosis. (2013) 227:420-4. doi: 10.1016/j.atherosclerosis.2013.01.013

48. Polyzos SA, Kountouras J, Mantzoros CS. Adipokines in nonalcoholic fatty liver disease. Metabolism. (2016). 65:1062-79. doi: 10.1016/j.metabol.2015.11.006

49. Smekal A, Vaclavik J. Adipokines and cardiovascular disease: a comprehensive review. Biomed Pap Med Fac Univ Palacky Olomouc Czech. Repub. (2017) 161, 31-40. doi: 10.5507/bp.2017.002

50. Ley RE, Peterson DA, Gordon JI. Ecological and evolutionary forces shaping microbial diversity in the human intestine. Cell. (2006) 124:837-48. doi: 10.1016/j.cell.2006.02.017

51. Curtiss LK, Tobias PS. Emerging role of Toll-like receptors in atherosclerosis. J Lipid Res. (2009). 50 (Suppl) S340-345. doi: 10.1194/jlr.R800056JLR200

52. Sanduzzi Zamparelli M, Compare D, Coccoli P, Rocco A, Nardone OM, Marrone G, et al. The metabolic role of gut microbiota in the development of nonalcoholic fatty liver disease and cardiovascular disease. Int J Mol Sci. (2016) 17:E1225. doi: 10.3390/ijms17081225

53. Wang $Z$, Tang WH, Buffa JA, Fu X, Britt EB, Koeth RA, et al. Prognostic value of choline and betaine depends on intestinal microbiotagenerated metabolite trimethylamine-N-oxide. Eur Heart J. (2014) 35:90410. doi: 10.1093/eurheartj/ehu002

54. Tang CS, Zhang H, Cheung CYY, Xu M, Ho JCY, Zhou W, et al. Exome-wide association analysis reveals novel coding sequence variants associated with lipid traits in Chinese. Nat Commun. (2015) 6:10206. doi: 10.1038/ncomms10206

55. Heuer M, Kaiser GM, Kahraman A, Banysch M, Saner FH, Mathe Z, et al. Liver transplantation in nonalcoholic steatohepatitis is associated with high mortality and post-transplant complications: a single-center experience. Digestion. (2012) 86:107-13. doi: 10.1159/000339344

56. Kotronen A, Westerbacka J, Bergholm R, Pietilainen KH, Yki-Jarvinen H. Liver fat in the metabolic syndrome. J Clin Endocrinol Metab. (2007) 92:3490-7. doi: 10.1210/jc.2007-0482

57. Liu H, Lu HY. Nonalcoholic fatty liver disease and cardiovascular disease. World J Gastroenterol. (2014) 20:8407-15. doi: 10.3748/wjg.v20.i26.8407

58. Donahue RP, Abbott RD, Bloom E, Reed DM, Yano K. Central obesity and coronary heart disease in men. Lancet. (1987) 1:821-4. doi: 10.1016/s0140-6736(87)91605-9

59. Semenkovich CF. Insulin resistance and atherosclerosis. J Clin Invest. (2006) 116:1813-22. doi: 10.1172/jci29024

60. Despres JP, Lemieux I, Bergeron J, Pibarot P, Mathieu P, Larose E, et al. Abdominal obesity and the metabolic syndrome: contribution to global cardiometabolic risk. Arterioscler Thromb Vasc Biol. (2008) 28:1039-49. doi: 10.1161/atvbaha.107.159228

61. Treeprasertsuk S, Leverage S, Adams LA, Lindor KD, St. Sauver J, Angulo P. The Framingham risk score and heart disease in nonalcoholic fatty liver disease. Liver Int. (2012) 32:945-50. doi: 10.1111/j.1478-3231.2011.02753.x

62. Blackett PR, Sanghera DK. Genetic determinants of cardiometabolic risk: a proposed model for phenotype association and interaction. J Clin Lipidol. (2013) 7:65-81. doi: 10.1016/j.jacl.2012.04.079

63. Chatrath H, Vuppalanchi R, Chalasani N. Dyslipidemia in patients with nonalcoholic fatty liver disease. Semin Liver Dis. (2012) 32:22-9. doi: $10.1055 / \mathrm{s}-0032-1306423$

64. Cheng VY, Dey D, Tamarappoo B, Nakazato R, Gransar H, Miranda-Peats R, et al. Pericardial fat burden on ECG-gated noncontrast $\mathrm{CT}$ in asymptomatic patients who subsequently experience adverse cardiovascular events. JACC Cardiovasc Imaging. (2010) 3:352-60. doi: 10.1016/j.jcmg.2009.12.013 
65. Kloner RA, Rezkalla SH.To drink or not to drink? That is the question. Circulation. (2007) 116:1306-17. doi: 10.1161/circulationaha.106.678375

66. Oliveira A, Rodriguez-Artalejo F, Lopes C. Alcohol intake and systemic markers of inflammation-shape of the association according to sex and body mass index. Alcohol Alcohol. (2010) 45:119-25. doi: 10.1093/alcalc/agp092

67. Blaha M, Budoff MJ, Shaw LJ, Khosa F, Rumberger JA, Berman D, et al. Absence of coronary artery calcification and all-cause mortality. JACC Cardiovasc Imaging. (2009) 2:692-700. doi: 10.1016/j.jcmg.2009.03.009

68. Sarwar A, Shaw LJ, Shapiro MD, Blankstein R, Hoffmann U, Cury RC, et al. Diagnostic and prognostic value of absence of coronary artery calcification. JACC Cardiovasc Imaging. (2009) 2:675-88. doi: 10.1016/j.jcmg.2008.12.031

69. Chang Y, Ryu S. Alcoholic and non-alcoholic fatty liver disease and associations with coronary artery calcification: evidence from the Kangbuk Samsung Health Study. Gut. (2018) 68:1667-75. doi: 10.1136/gutjnl-2018-317666

70. Kim MK, Ahn CW, Nam JS, Kang S, Park JS, Kim KR. (2015). Association between nonalcoholic fatty liver disease and coronary artery calcification in postmenopausal women. Menopause. 22, 1323-1327. doi: 10.1097/gme.0000000000000503

71. Wolff L, Hofman A, Bos D, Krestin GP, Vernooij MW, Franco OH, et al. Liver fat is related to cardiovascular risk factors and subclinical vascular disease: the Rotterdam Study. Eur Heart J-Card Img. (2016) 17:1361-7. doi: 10.1093/ehjci/jew174

72. Kim BJ, Cheong ES, Kang JG, Kim BS, Kang JH. Relationship of epicardial fat thickness and nonalcoholic fatty liver disease to coronary artery calcification: from the CAESAR study. J Clin Lipidol. (2016) 10:619-26.e611. doi: 10.1016/j.jacl.2016.01.008

73. Jacobs K, Brouha S, Bettencourt R, Barrett-Connor E, Sirlin C, Loomba R. Association of nonalcoholic fatty liver disease with visceral adiposity but not coronary artery calcification in the elderly. Clin Gastroenterol Hepatol. (2016) 14:1337-44.e1333. doi: 10.1016/j.cgh.2016.01.010

74. Lee MK, Park HJ, Jeon WS, Park SE, Park CY, Lee WY, et al. Higher association of coronary artery calcification with non-alcoholic fatty liver disease than with abdominal obesity in middle-aged Korean men: the Kangbuk Samsung Health Study. Cardiovasc Diabetol. (2015) 14:88. doi: 10.1186/s12933-015-0253-9

75. Vanwagner LB, Ning H, Lewis CE, Shay CM, Wilkins J, Carr JJ, et al. Associations between nonalcoholic fatty liver disease and subclinical atherosclerosis in middle-aged adults: the coronary artery risk development in young adults study. Atherosclerosis. (2014) 235:599-605. doi: 10.1016/j.atherosclerosis.2014.05.962

76. Jung DH, Lee YJ, Ahn HY, Shim JY, Lee HR. Relationship of hepatic steatosis and alanine aminotransferase with coronary calcification. Clin Chem Lab Med. (2010) 48:1829-34. doi: 10.1515/cclm.2010.349

77. Arslan U, Turkoglu S, Balcioglu S, Tavil Y, Karakan T, Cengel A. Association between nonalcoholic fatty liver disease and coronary artery disease. Coron Artery Dis. (2007) 18:433-6. doi: 10.1097/MCA.0b013e3282583c0d

78. Mirbagheri SA, Rashidi A, Abdi S, Saedi D, Abouzari M. Liver: an alarm for the heart? Liver Int. (2007) 27:891-4. doi: 10.1111/j.1478-3231.2007.01531.x

79. Acikel M, Sunay S, Koplay M, Gundogdu F, Karakelleoglu S. Evaluation of ultrasonographic fatty liver and severity of coronary atheroscledrosis, and obesity in patients undergoing coronary angiography. Anadolu Kardiyol Derg. (2009) 9:273-79. Available online at: http://www.anatoljcardiol.com/ jvi.aspx? un=AJC-93359

80. You SC, Kim KJ, Kim SU, Kim BK, Park JY, Kim DY, et al. Hepatic fibrosis assessed using transient elastography independently associated with coronary artery calcification. J Gastroenterol Hepatol. (2015) 30:1536-42. doi: 10.1111/jgh.12992

81. Cobble M, Bale B. Carotid intima-media thickness: knowledge and application to everyday practice. Postgrad Med. (2010) 122:10-18. doi: 10.3810/pgm.2010.01.2091

82. O’leary DH, Polak JF, Kronmal RA, Manolio TA, Burke GL, Wolfson SK Jr. Carotid-artery intima and media thickness as a risk factor for myocardial infarction and stroke in older adults. Cardiovascular Health Study Collaborative Research Group. N Engl J Med. (1999) 340, 14-22. doi: 10.1056/nejm199901073400103

83. Lorenz MW, Markus HS, Bots ML, Rosvall M, Sitzer M. Prediction of clinical cardiovascular events with carotid intima-media thickness: a systematic review and meta-analysis. Circulation. (2007) 115:459-467. doi: 10.1161/circulationaha.106.628875

84. Oni ET, Agatston AS, Blaha MJ, Fialkow J, Cury R, Sposito A, et al. A systematic review: burden and severity of subclinical cardiovascular disease among those with nonalcoholic fatty liver; should we care? Atherosclerosis. (2013) 230:258-67. doi: 10.1016/j.atherosclerosis.2013.07.052

85. Sookoian S, Pirola CJ. Non-alcoholic fatty liver disease is strongly associated with carotid atherosclerosis: a systematic review. J Hepatol. (2008) 49:600-7. doi: 10.1016/j.jhep.2008.06.012

86. Mishra S, Yadav D, Gupta M, Mishra H, Sharma P. A study of carotid atherosclerosis in patients with non-alcoholic fatty liver disease. Indian J Clin Biochem. (2013) 28:79-83. doi: 10.1007/s12291-0120286-8

87. Kim HJ, Lim CW, Lee JH, Park HB, Suh Y, Cho YH, et al. Gender-based differences in the relationship between fatty liver disease and atherosclerosis. Cardiovasc J Afr. (2016) 27:281-6. doi: 10.5830/cvja-2016-014

88. Martinez-Alvarado Mdel R, Juarez-Rojas JG, Medina-Urrutia AX, CardosoSaldana GC, Gonzalez-Salazar Mdel C, Posadas-Sanchez R, et al. Association of fatty liver with cardiovascular risk factors and subclinical atherosclerosis in a Mexican population. Rev Invest Clin. (2014) 66:407-14. Available online at: https://www.medigraphic.com/cgi-bin/new/resumenI.cgi? IDARTICULO $=55276$

89. Li X, Shi H, Wang Z, Chang L, Zhang M, Dong X. Arterial stiffness is increased in nondiabetic, nonhypertensive postmenopausal women with nonalcoholic fatty liver disease. J Hypertens. (2017) 35:1226-34. doi: 10.1097/hjh.0000000000001285

90. Petit JM, Guiu B, Terriat B, Loffroy R, Robin I, Petit V, et al. Nonalcoholic fatty liver is not associated with carotid intima-media thickness in type 2 diabetic patients. J Clin Endocrinol Metab. (2009) 94:4103-6. doi: 10.1210/jc.2009-0541

91. Nahandi MZ, Khoshbaten M, Ramazanzadeh E, Abbaszadeh L, Javadrashid $\mathrm{R}$, Shirazi KM, et al. Effect of non-alcoholic fatty liver disease on carotid artery intima-media thickness as a risk factor for atherosclerosis. Gastroenterol Hepatol Bed Bench. (2014) 7:55-62.

92. Targher G, Bertolini L, Padovani R, Rodella S, Zoppini G, Zenari L, et al. Relations between carotid artery wall thickness and liver histology in subjects with nonalcoholic fatty liver disease. Diabetes Care. (2006) 29:1325-30. doi: $10.2337 / \mathrm{dc06}-0135$

93. Mohammadi A, Bazazi A, Maleki-Miyandoab T, Ghasemi-Rad M. Evaluation of relationship between grading of fatty liver and severity of atherosclerotic finding. Int J Clin Exp Med. (2012) 5:251-6.

94. Bhatia L, Scorletti E, Curzen N, Clough GF, Calder PC, Byrne CD. Improvement in non-alcoholic fatty liver disease severity is associated with a reduction in carotid intima-media thickness progression. Atherosclerosis. (2016) 246:13-20. doi: 10.1016/j.atherosclerosis.2015.12.028

95. Targher G, Bertolini L, Padovani R, Zenari L, Zoppini G, Falezza G. Relation of nonalcoholic hepatic steatosis to early carotid atherosclerosis in healthy men. role of visceral fat accumulation. Diabetes Care. (2004) 27:2498-500. doi: $10.2337 /$ diacare.27.10.2498

96. Arinc H, Sarli B, Baktir AO, Saglam H, Demirci E, Dogan Y, et al. Serum gamma glutamyl transferase and alanine transaminase concentrations predict endothelial dysfunction in patients with non-alcoholic steatohepatitis. UPS J Med Sci. (2013) 118:228-34. doi: 10.3109/03009734.2013.814734

97. Mckimmie RL, Daniel KR, Carr JJ, Bowden DW, Freedman BI, Register TC, et al. Hepatic steatosis and subclinical cardiovascular disease in a cohort enriched for type 2 diabetes: the Diabetes Heart Study. Am J Gastroenterol. (2008) 103:3029-35. doi: 10.1111/j.1572-0241.2008.02188.x

98. Kim JH, Kim SY, Jung ES, Jung SW, Koo JS, Kim JH, et al. Carotid intimamedia thickness is increased not only in non-alcoholic fatty liver disease patients but also in alcoholic fatty liver patients. Digestion. (2011) 84:149-55. doi: 10.1159/000326854

99. Qu B-G, Wang H, Liu Y-X, Jia Y-G, Su J-L, Wang Z-D, et al. Causes of thickening of carotid intima-media thickness in patients with alcoholic liver disease: a prospective observational study. Medicine. (2015) 94:e1087-e1087. doi: 10.1097/MD.0000000000001087

100. Bao-Ge Q, Hui W, Yi-Guo J, Ji-Liang S, Zhong-Dong W, Ya-Fei W, et al. The correlation and risk factors between carotid intima-media thickening 
and alcoholic liver disease coupled with helicobacter pylori infection. Sci Rep. (2017) 7:43059. doi: 10.1038/srep43059

101. Azzam H, Malnick S. Non-alcoholic fatty liver disease - the heart of the matter. World J Hepatol. (2015) 7:1369-76. doi: 10.4254/wjh.v7.i10.1369

102. Petta S, Argano C, Colomba D, Camma C, Di Marco V, Cabibi D, et al. Epicardial fat, cardiac geometry and cardiac function in patients with nonalcoholic fatty liver disease: association with the severity of liver disease. $J$ Hepatol. (2015) 62:928-33. doi: 10.1016/j.jhep.2014.11.030

103. Yilmaz Y, Kurt R, Yonal O, Polat N, Celikel CA, Gurdal A, et al. Coronary flow reserve is impaired in patients with nonalcoholic fatty liver disease: association with liver fibrosis. Atherosclerosis. (2010) 211:182-6. doi: 10.1016/j.atherosclerosis.2010.01.049

104. Mahfouz RA, Gouda M, Galal I, Ghareb MS. Interatrial septal fat thickness and left atrial stiffness are mechanistic links between nonalcoholic fatty liver disease and incident atrial fibrillation. Echocardiography. (2019) 36:249-56. doi: 10.1111/echo.14229

105. Oguz D, Unal HU, Eroglu H, Gulmez O, Cevik H, Altun A. Aortic flow propagation velocity, epicardial fat thickness, and osteoprotegerin level to predict subclinical atherosclerosis in patients with nonalcoholic fatty liver disease. Anatol J Cardiol. (2016) 16:974-79. doi: 10.14744/AnatolJCardiol.2016.6706

106. Baragetti A, Pisano G, Bertelli C, Garlaschelli K, Grigore L, Fracanzani AL, et al. Subclinical atherosclerosis is associated with epicardial fat thickness and hepatic steatosis in the general population. Nutr Metab Cardiovasc Dis. (2016) 26:141-53. doi: 10.1016/j.numecd.2015.10.013

107. Sunbul M, Agirbasli M, Durmus E, Kivrak T, Akin H, Aydin Y, et al. Arterial stiffness in patients with non-alcoholic fatty liver disease is related to fibrosis stage and epicardial adipose tissue thickness. Atherosclerosis. (2014) 237:490-3. doi: 10.1016/j.atherosclerosis.2014.10.004

108. Psychari SN, Rekleiti N, Papaioannou N, Varhalama E, Drakoulis C, Apostolou TS, et al. Epicardial fat in nonalcoholic fatty liver disease: properties and relationships with metabolic factors, cardiac structure, and cardiac function. Angiology. (2016) 67:41-8. doi: 10.1177/0003319715576672

109. Finucci G, Desideri A, Sacerdoti D, Bolognesi M, Merkel C, Angeli P, et al. Left ventricular diastolic function in liver cirrhosis. Scand J Gastroenterol. (1996) 31:279-84.

110. Milić S, Lulić D, Štimac D, RuŽić A, Zaputovic L. Cardiac manifestations in alcoholic liver disease. Postgrad Med J. (2016) 92:235-9. doi: 10.1136/postgradmedj-2015-133755

111. Volzke H, Haring R, Lorbeer R, Wallaschofski H, Reffelmann $\mathrm{T}$, Empen $\mathrm{K}$, et al. Heart valve sclerosis predicts all-cause and cardiovascular mortality. Atherosclerosis. (2010) 209:606-10. doi: 10.1016/j.atherosclerosis.2009.10.030

112. Otto CM, Prendergast B. Aortic-valve stenosis-from patients at risk to severe valve obstruction. $N$ Engl J Med. (2014) 371:744-56. doi: 10.1056/NEJMra1313875

113. Anstee QM, Mantovani A, Tilg H, Targher G. Risk of cardiomyopathy and cardiac arrhythmias in patients with nonalcoholic fatty liver disease. Nat Rev Gastroenterol Hepatol. (2018) 15:425-39. doi: 10.1038/s41575-018-0010-0

114. Markus MR, Baumeister SE, Stritzke J, Dorr M, Wallaschofski H, Volzke H, et al. Hepatic steatosis is associated with aortic valve sclerosis in the general population: the Study of Health in Pomerania (SHIP). Arterioscler Thromb Vasc Biol. (2013) 33:1690-5. doi: 10.1161/atvbaha.112.300556

115. Bonapace S, Valbusa F, Bertolini L, Pichiri I, Mantovani A, Rossi A, et al. Nonalcoholic fatty liver disease is associated with aortic valve sclerosis in patients with type 2 diabetes mellitus. PLoS ONE. (2014) 9:e88371. doi: 10.1371/journal.pone.0088371

116. Mantovani A, Pernigo M, Bergamini C, Bonapace S, Lipari P, Valbusa $F$, et al. Heart valve calcification in patients with type 2 diabetes and nonalcoholic fatty liver disease. Metabolism. (2015) 64:879-87. doi: 10.1016/j.metabol.2015.04.003

117. Mantovani A, Dauriz M, Sandri D, Bonapace S, Zoppini G, Tilg H, et al. Association between non-alcoholic fatty liver disease and risk of atrial fibrillation in adult individuals: an updated meta-analysis. Liver Int. (2019) 39:758-69. doi: 10.1111/liv.14044

118. Zhang Y, Li P, Miao M, Liu Y, Pan Y, Xu L, et al. Nonalcoholic fatty liver disease is associated with increased atrial fibrillation risk in an elderly chinese population: a cross-sectional study. (2018) 2018:5628749. doi: 10.1155/2018/5628749

119. Markus MR, Meffert PJ, Baumeister SE, Lieb W, Siewert U, Schipf S, et al. Association between hepatic steatosis and serum liver enzyme levels with atrial fibrillation in the general population: The Study of Health in Pomerania (SHIP). Atherosclerosis. (2016) 245:123-31. doi: 10.1016/j.atherosclerosis.2015.12.023

120. Mantovani A. NAFLD and risk of cardiac arrhythmias: is hyperuricemia a neglected pathogenic mechanism? Dig Liver Dis. (2018) 50:518-20. doi: 10.1016/j.dld.2018.02.002

121. Mantovani A, Rigamonti A, Bonapace S, Bolzan B, Pernigo M, Morani $\mathrm{G}$, et al. Nonalcoholic fatty liver disease is associated with ventricular arrhythmias in patients with type 2 diabetes referred for clinically indicated 24-hour holter monitoring. Diabetes Care. (2016) 39:1416-23. doi: $10.2337 / \mathrm{dc16}-0091$

122. Hung CS, Tseng PH, Tu CH, Chen CC, Liao WC, Lee YC, et al. Nonalcoholic fatty liver disease is associated with qt prolongation in the general population. J Am Heart Assoc. (2015) 4. doi: 10.1161/jaha.115.001820

123. Mantovani A, Rigolon R, Pichiri I, Bonapace S, Morani G, Zoppini G, et al. Nonalcoholic fatty liver disease is associated with an increased risk of heart block in hospitalized patients with type 2 diabetes mellitus. PLoS ONE. (2017) 12:e0185459. doi: 10.1371/journal.pone.0185459

124. Iscen S. RBBB is associated with an increased risk of NAFLD in young healthy individuals. Int $J$ Cardiol. (2013) 168:4056-7. doi: 10.1016/j.ijcard.2013.07.035

125. Ozveren O, Dogdu O, Sengul C, Cinar V, Eroglu E, Kucukdurmaz Z, et al. Deterioration of heart rate recovery index in patients with nonalcoholic fatty liver disease (NAFLD). Med Sci Monit. (2014) 20:1539-43. doi: $10.12659 / \mathrm{msm} .890741$

126. Dyson JK, Anstee QM, Mcpherson S. Non-alcoholic fatty liver disease: a practical approach to treatment. Front Gastroenterol. (2014) 5:277-86. doi: 10.1136/flgastro-2013-100404

127. Fontana L, Meyer TE, Klein S, Holloszy JO. Long-term calorie restriction is highly effective in reducing the risk for atherosclerosis in humans. Proc Natl Acad Sci USA. (2004) 101:6659-63. doi: 10.1073/pnas.0308291101

128. Vilar-Gomez E, Martinez-Perez Y, Calzadilla-Bertot L, TorresGonzalez A, Gra-Oramas B, Gonzalez-Fabian L, et al. Weight loss through lifestyle modification significantly reduces features of nonalcoholic steatohepatitis. Gastroenterology. (2015) 149:367-378.e365. doi: 10.1053/j.gastro.2015.04.005

129. Zivkovic AM, German JB, Sanyal AJ. Comparative review of diets for the metabolic syndrome: implications for nonalcoholic fatty liver disease. Am J Clin Nutr. (2007) 86:285-300. doi: 10.1093/ajcn/86.2.285

130. Borrelli A, Bonelli P, Tuccillo FM, Goldfine ID, Evans JL, Buonaguro $\mathrm{FM}$, et al. Role of gut microbiota and oxidative stress in the progression of non-alcoholic fatty liver disease to hepatocarcinoma: current and innovative therapeutic approaches. Redox Biol. (2018) 15:467-79. doi: 10.1016/j.redox.2018.01.009

131. Ryan MC, Itsiopoulos C, Thodis T, Ward G, Trost N, Hofferberth S, et al. The Mediterranean diet improves hepatic steatosis and insulin sensitivity in individuals with non-alcoholic fatty liver disease. J Hepatol. (2013) 59:13843. doi: 10.1016/j.jhep.2013.02.012

132. Kennedy OJ, Roderick P, Buchanan R, Fallowfield JA, Hayes PC, Parkes J. Systematic review with meta-analysis: coffee consumption and the risk of cirrhosis. Aliment Pharmacol Ther. (2016) 43:562-74. doi: 10.1111/apt.13523

133. Diehl AM, Day C. Cause, pathogenesis, and treatment of nonalcoholic steatohepatitis. N Engl J Med. (2017) 377:2063-72. doi: 10.1056/NEJMra1503519

134. Musso G, Cassader M, Rosina F, Gambino R. Impact of current treatments on liver disease, glucose metabolism and cardiovascular risk in non-alcoholic fatty liver disease (NAFLD): a systematic review and meta-analysis of randomised trials. Diabetologia. (2012) 55:885-904. doi: 10.1007/s00125-011-2446-4

135. Glass LM, Dickson RC, Anderson JC, Suriawinata AA, Putra J, Berk BS, et al. Total body weight loss of $>/=10 \%$ is associated with improved hepatic fibrosis in patients with nonalcoholic steatohepatitis. Dig Dis Sci. (2015) 60:1024-30. doi: 10.1007/s10620-014-3380-3 
136. Heneghan HM, Meron-Eldar S, Brethauer SA, Schauer PR, Young JB. Effect of bariatric surgery on cardiovascular risk profile. Am J Cardiol. (2011) 108:1499-507. doi: 10.1016/j.amjcard.2011.06.076

137. Mahajan R, Lau DH, Sanders P. Impact of obesity on cardiac metabolism, fibrosis, and function. Trends Cardiovasc Med. (2015) 25:119-26. doi: 10.1016/j.tcm.2014.09.005

138. Karimian S, Stein J, Bauer B, Teupe C. Improvement of impaired diastolic left ventricular function after diet-induced weight reduction in severe obesity. Diabetes Metab Syndr Obes. (2017) 10:19-25. doi: 10.2147/dmso.s124541

139. Bozkurt B, Deswal A. Obesity as a prognostic factor in chronic symptomatic heart failure. Am Heart J. (2005) 150:1233-39. doi: 10.1016/j.ahj.2005.02.004

140. Gupta PP, Fonarow GC, Horwich TB. Obesity and the obesity paradox in heart failure. Can $J$ Cardiol. (2015) 31:195-202. doi: 10.1016/j.cjca.2014.08.004

141. Oni ET, Kalathiya R, Aneni EC, Martin SS, Blaha MJ, Feldman T, et al. Relation of physical activity to prevalence of nonalcoholic fatty liver disease independent of cardiometabolic risk. Am J Cardiol. (2015) 115:34-9. doi: 10.1016/j.amjcard.2014.09.044

142. Koo BK, Kim D, Joo SK, Kim JH, Chang MS, Kim BG, et al. Sarcopenia is an independent risk factor for non-alcoholic steatohepatitis and significant fibrosis. J Hepatol. (2017) 66:123-31. doi: 10.1016/j.jhep.2016.08.019

143. Kirwan JP, Solomon TP, Wojta DM, Staten MA, Holloszy JO. Effects of 7 days of exercise training on insulin sensitivity and responsiveness in type 2 diabetes mellitus. Am J Physiol Endocrinol Metab. (2009) 297:E151-156. doi: 10.1152/ajpendo.00210.2009

144. Van Der Heijden GJ, Wang ZJ, Chu Z, Toffolo G, Manesso E, Sauer PJ, et al. Strength exercise improves muscle mass and hepatic insulin sensitivity in obese youth. Med Sci Sports Exerc. (2010) 42:1973-80. doi: 10.1249/MSS.0b013e3181df16d9

145. Zhang H-J, He J, Pan L-L, Ma Z-M, Han C-K, Chen C-S, et al. Effects of moderate and vigorous exercise on nonalcoholic fatty liver disease: a randomized clinical trialeffects of exercise on nonalcoholic fatty liver diseaseeffects of exercise on nonalcoholic fatty liver disease. JAMA Int Med. (2016) 176:1074-82. doi: 10.1001/jamainternmed.2016.3202

146. Orci LA, Gariani K, Oldani G, Delaune V, Morel P, Toso C. Exercisebased Interventions for nonalcoholic fatty liver disease: a meta-analysis and meta-regression. Clin Gastroenterol Hepatol. (2016) 14:1398-411. doi: 10.1016/j.cgh.2016.04.036

147. Lin JS, O'connor E, Evans CV, Senger CA, Rowland MG, Groom HC. Behavioral counseling to promote a healthy lifestyle in persons with cardiovascular risk factors: a systematic review for the U. S. Preventive Services Task Force. Ann Intern Med. (2014) 161, 68-578. doi: $10.7326 / \mathrm{m} 14-0130$

148. Hallsworth K, Thoma C, Hollingsworth KG, Cassidy S, Anstee QM, Day $\mathrm{CP}$, et al. Modified high-intensity interval training reduces liver fat and improves cardiac function in non-alcoholic fatty liver disease: a randomized controlled trial. Clin Sci. (2015) 129:1097-105. doi: 10.1042/cs201 50308

149. Ratziu V. Non-pharmacological interventions in non-alcoholic fatty liver disease patients. Liver Int. (2017) 37:90-6. doi: 10.1111/liv.13311

150. Ratziu V, Goodman Z, Sanyal A. Current efforts and trends in the treatment of NASH. J Hepatol. (2015) 62:S65-75. doi: 10.1016/j.jhep.2015.02.041

151. Zheng SL, Roddick AJ. Association of aspirin use for primary prevention with cardiovascular events and bleeding events: a systematic review and meta-analysisassociation of aspirin use for primary prevention of CVD with cardiovascular events and bleedingassociation of aspirin use for primary prevention of CVD with cardiovascular events and bleeding. JAMA. (2019) 321:277-87. doi: 10.1001/jama.2018.20578

152. Jiang ZG, Feldbrügge L, Tapper EB, Popov Y, Ghaziani T, Afdhal N, et al. Aspirin use is associated with lower indices of liver fibrosis among adults in the United States. Aliment Pharmacol Ther. (2016) 43:734-43. doi: 10.1111/apt.13515

153. Simon TG, Henson J, Osganian S, Masia R, Chan AT, Chung RT, et al. Daily aspirin use associated with reduced risk for fibrosis progression in patients with nonalcoholic fatty liver disease. Clin Gastroenterol Hepatol. (2019). doi: 10.1016/j.cgh.2019.04.061. [Epub ahead of print].

154. Yokohama S, Yoneda M, Haneda M, Okamoto S, Okada M, Aso K, et al. Therapeutic efficacy of an angiotensin II receptor antagonist in patients with nonalcoholic steatohepatitis. Hepatology. (2004) 40:1222-5. doi: 10.1002/hep. 20420

155. Georgescu EF, Ionescu R, Niculescu M, Mogoanta L, Vancica L. Angiotensinreceptor blockers as therapy for mild-to-moderate hypertension-associated non-alcoholic steatohepatitis. World J Gastroenterol. (2009) 15:942-54. doi: 10.3748/wjg.15.942

156. Musso G, Gambino R, Cassader M, Pagano G. A meta-analysis of randomized trials for the treatment of nonalcoholic fatty liver disease. Hepatology. (2010) 52:79-104. doi: 10.1002/hep.23623

157. Targher G, Byrne CD. Non-alcoholic fatty liver disease: an emerging driving force in chronic kidney disease. Nat Rev Nephrol. (2017) 13:297. doi: 10.1038/nrneph.2017.16

158. Pelusi S, Petta S, Rosso C, Borroni V, Fracanzani AL, Dongiovanni P, et al. Renin-angiotensin system inhibitors, Type 2 diabetes and fibrosis progression: an observational study in patients with nonalcoholic fatty liver disease. PLoS ONE. (2016) 11:e0163069. doi: 10.1371/journal.pone.01 63069

159. Musso G, Gambino R, Cassader M, Pagano G. Meta-analysis: Natural history of non-alcoholic fatty liver disease (NAFLD) and diagnostic accuracy of non-invasive tests for liver disease severity. Ann Med. (2011) 43:617-49. doi: $10.3109 / 07853890.2010 .518623$

160. De Keyser CE, Koehler EM, Schouten JNL, Visser LE, Hofman A, Janssen HLA, et al. Statin therapy is associated with a reduced risk of nonalcoholic fatty liver in overweight individuals. Dig Liver Dis. (2014) 46:720-5. doi: 10.1016/j.dld.2014.04.002

161. Oni ET, Sinha P, Karim A, Martin SS, Blaha MJ, Agatston AS, et al. Statin use is not associated with presence of and severity of nonalcoholic fatty liver disease. Arch Med Res. (2014) 45:52-7. doi: 10.1016/j.arcmed.2013.12.003

162. Taylor F, Ward K, Moore TH, Burke M, Davey Smith G, Casas JP, et al. Statins for the primary prevention of cardiovascular disease. Cochrane Database Syst Rev. (2011) Cd004816. doi: 10.1002/14651858.CD004816.pub4

163. Keene D, Price C, Shun-Shin MJ, Francis DP. Effect on cardiovascular risk of high density lipoprotein targeted drug treatments niacin, fibrates, and CETP inhibitors: meta-analysis of randomised controlled trials including 117411 patients. BMJ Br Med J. (2014) 349:g4379. doi: 10.1136/bmj.g4379

164. Tikkanen MJ, Fayyad R, Faergeman O, Olsson AG, Wun C-C, Laskey R, et al. Effect of intensive lipid lowering with atorvastatin on cardiovascular outcomes in coronary heart disease patients with mild-to-moderate baseline elevations in alanine aminotransferase levels. Int J Cardiol. (2013) 168:384652. doi: 10.1016/j.ijcard.2013.06.024

165. Wiklund O, Pirazzi C, Romeo S. Monitoring of lipids, enzymes, and creatine kinase in patients on lipid-lowering drug therapy. Curr Cardiol Rep. (2013) 15:397. doi: 10.1007/s11886-013-0397-8

166. Athyros VG, Tziomalos K, Gossios TD, Griva T, Anagnostis P, Kargiotis K, et al. Safety and efficacy of long-term statin treatment for cardiovascular events in patients with coronary heart disease and abnormal liver tests in the Greek atorvastatin and coronary Heart Disease Evaluation (GREACE) Study: a post-hoc analysis. Lancet. (2010) 376:1916-22. doi: 10.1016/S0140-6736(10)61272-X

167. Stroes ES, Thompson PD, Corsini A, Vladutiu GD, Raal FJ, Ray KK, et al. Statin-associated muscle symptoms: impact on statin therapyEuropean Atherosclerosis Society Consensus Panel Statement on Assessment, Aetiology and Management. Eur Heart J. (2015) 36:1012-22. doi: 10.1093/eurheartj/ehv043

168. Sanyal AJ, Abdelmalek MF, Suzuki A, Cummings OW, Chojkier M. No significant effects of ethyl-eicosapentanoic acid on histologic features of nonalcoholic steatohepatitis in a phase 2 trial. Gastroenterology. (2014) 147:377-384.e371. doi: 10.1053/j.gastro.2014.04.046

169. Argo CK, Patrie JT, Lackner C, Henry TD, De Lange EE, Weltman AL, et al. Effects of n-3 fish oil on metabolic and histological parameters in NASH: a double-blind, randomized, placebo-controlled trial. J Hepatol. (2015) 62:190-7. doi: 10.1016/j.jhep.2014.08.036

170. Lu W, Li S, Li J, Wang J, Zhang R, Zhou Y, et al. Effects of Omega-3 fatty acid in nonalcoholic fatty liver disease: a meta-analysis. Gastroenterol Res Pract. (2016) 2016:11. doi: 10.1155/2016/1459790

171. Li Y, Liu L, Wang B, Wang J, Chen D. Metformin in non-alcoholic fatty liver disease: a systematic review and meta-analysis. Biomed Rep. (2013) 1:57-64. doi: $10.3892 /$ br. 2012.18 
172. Singh S, Singh PP, Singh AG, Murad MH, Sanchez W. Anti-diabetic medications and the risk of hepatocellular cancer: a systematic review and meta-analysis. Am J Gastroenterol. (2013) 108:881-891; quiz 892. doi: 10.1038/ajg.2013.5

173. Bhat A, Sebastiani G, Bhat M. Systematic review: preventive and therapeutic applications of metformin in liver disease. World J Hepatol. (2015). 7:1652-9. doi: 10.4254/wjh.v7.i12.1652

174. Mohan M, Al-Talabany S, Mckinnie AM, Mordi I, Singh JS, Gandy SJ, et al. Metformin regresses left ventricular hypertrophy in normotensive patients with coronary artery disease without type 2 diabetes mellitus-The METREMODEL trial. Diabetes. (2018) 67, 167-OR. doi: 10.2337/db18-167-OR

175. Sanyal AJ, Chalasani N, Kowdley KV, Mccullough A, Diehl AM, Bass NM, et al. Pioglitazone, vitamin E, or placebo for nonalcoholic steatohepatitis. $N$ Engl J Med. (2010) 362:1675-85. doi: 10.1056/NEJMoa0907929

176. Cusi K, Orsak B, Bril F, Lomonaco R, Hecht J, Ortiz-Lopez C, et al. Longterm pioglitazone treatment for patients with nonalcoholic steatohepatitis and prediabetes or type 2 diabetes mellitus: a randomized trial. Ann Intern Med. (2016) 165:305-15. doi: 10.7326/m15-1774

177. Armstrong MJ, Gaunt P, Aithal GP, Barton D, Hull D, Parker R, et al. Liraglutide safety and efficacy in patients with non-alcoholic steatohepatitis (LEAN): a multicentre, double-blind, randomised, placebo-controlled phase 2 study. Lancet. (2016) 387:679-90. doi: 10.1016/s0140-6736(15)00803-x

178. European Association for the Study of the Liver (EASL), European Association for the Study of Diabetes (EASD), European Association for the Study of Obesity (EASO). EASL-EASD-EASO Clinical practice guidelines for the management of non-alcoholic fatty liver disease. J Hepatol. (2016) 64:1388-402. doi: 10.1016/j.jhep.2015.11.004

179. Petit JM, Cercueil JP, Loffroy R, Denimal D, Bouillet B, Fourmont C, et al. Effect of liraglutide therapy on liver fat content in patients with inadequately controlled Type 2 diabetes: the Lira-NAFLD Study. J Clin Endocrinol Metab. (2017) 102:407-15. doi: 10.1210/jc.2016-2775

180. Marso SP, Daniels GH, Brown-Frandsen K, Kristensen P, Mann JFE, Nauck MA, et al. Liraglutide and cardiovascular outcomes in type 2 diabetes. $N$ Engl J Med. (2016) 375:311-22. doi: 10.1056/NEJMoa1603827
181. Scheen AJ. Beneficial effects of SGLT2 inhibitors on fatty liver in type 2 diabetes: a common comorbidity associated with severe complications. Diabetes Metab. (2019) 45:213-23. doi: 10.1016/j.diabet.2019. 01.008

182. Cui J, Philo L, Nguyen P, Hofflich H, Hernandez C, Bettencourt R, et al. Sitagliptin vs. placebo for non-alcoholic fatty liver disease: a randomized controlled trial. J Hepatol. (2016) 65:369-76. doi: 10.1016/j.jhep.2016.04.021

183. Ratziu V, Harrison SA, Francque S, Bedossa P, Lehert P, Serfaty L, et al. Elafibranor, an agonist of the peroxisome proliferator-activated receptor $-\alpha$ and $-\delta$, induces resolution of nonalcoholic steatohepatitis without fibrosis worsening. Gastroenterology. (2016) 150:1147-1159.e1145. doi: 10.1053/j.gastro.2016.01.038

184. Perazzo H, Dufour JF. The therapeutic landscape of non-alcoholic steatohepatitis. Liver Int. (2017) 37:634-47. doi: 10.1111/liv.13270

185. Neuschwander-Tetri BA, Loomba R, Sanyal AJ, Lavine JE, Van Natta ML, Abdelmalek MF, et al. Farnesoid X nuclear receptor ligand obeticholic acid for non-cirrhotic, non-alcoholic steatohepatitis (FLINT): a multicentre, randomised, placebo-controlled trial. Lancet. (2015) 385:956-65. doi: 10.1016/s0140-6736(14)61933-4

186. Taitano AA, Markow M, Finan JE, Wheeler DE, Gonzalvo JP, Murr MM. Bariatric surgery improves histological features of nonalcoholic fatty liver disease and liver fibrosis. J Gastrointest Surg. (2015) 19:429-37. doi: $10.1007 /$ s11605-014-2678-y

Conflict of Interest Statement: The authors declare that the research was conducted in the absence of any commercial or financial relationships that could be construed as a potential conflict of interest.

Copyright (C) 2019 Ismaiel and Dumitraşcu. This is an open-access article distributed under the terms of the Creative Commons Attribution License (CC BY). The use, distribution or reproduction in other forums is permitted, provided the original author(s) and the copyright owner(s) are credited and that the original publication in this journal is cited, in accordance with accepted academic practice. No use, distribution or reproduction is permitted which does not comply with these terms. 